\title{
HTGR Fuel Development: Investigations of B reakages of Uranium-Loaded Weak Acid Resin Microspheres
}

J. A. Carpenter, Jr.

\section{MASTR}




\section{DISCLAIMER}

This report was prepared as an account of work sponsored by an agency of the United States Government. Neither the United States Government nor any agency Thereof, nor any of their employees, makes any warranty, express or implied, or assumes any legal liability or responsibility for the accuracy, completeness, or usefulness of any information, apparatus, product, or process disclosed, or represents that its use would not infringe privately owned rights. Reference herein to any specific commercial product, process, or service by trade name, trademark, manufacturer, or otherwise does not necessarily constitute or imply its endorsement, recommendation, or favoring by the United States Government or any agency thereof. The views and opinions of authors expressed herein do not necessarily state or reflect those of the United States Government or any agency thereof. 


\section{DISCLAIMER}

Portions of this document may be illegible in electronic image products. Images are produced from the best available original document. 
Printed in the United Stales of America. Avallable from National Technical Information Service

U.S. Department of Commerce 5285 Port Royal Road, Springfield, Virginia 22161

Price: Printed Copy $\$ 4,50$; Microfiche $\$ 3.00$

This report was prepared as an account of work sponsored by the United States Government. Neither the United States nor the Energy Research and Development Administration/United States Nuclear Regulatory Commission, nor any of their employees, nor any of their contractors, subcontractors, or their employees, makes any warranty, express or implied, or assumes any legal liability or responsibility for the accuracy, completeness or usefulness of any information, apparatus, product or process disclosed, or represents that its use would not infringe privately owned rights. 
ORNL/ TM-6067

Distribution

Category UC-77

\author{
Contract No. W-7405-eng-26 \\ METALS AND CERAMICS DIVISION
}

THORIUM UTILIZATION PROGRAM (189a OHO45)

Refabrication Development - Task 300

HTGR FUEL DEVELOPMENT: INVESTIGATIONS OF BREAKAGES OF URANIUM-LOADED WEAK ACID RESIN MICROSPHERES

J. A. Carpenter, Jr.

Date Published: November 1977

\author{
OAK RIDGE NATIONAL LABORATORY \\ Oak Ridge, Tennessee 37830 \\ operated by \\ UNION CARBIDE CORPORATION \\ for the \\ DEPARTMENT OF ENERGY
}


THIS PAGE

\section{WAS INTENTIONALLY LEFT BLANK}


CONTENTS

ABSTRACT . . . . . . . . . . . . . . . . . . . . . 1

INTRODUCTION . . . . . . . . . . . . . . . . . . . . 1

FAILURE OF AMBERLITE IRC-72 DURING CARBONIZATION AND PNEUMATIC

TRANSFER . . . . . . . . . . . . . . . . . . . . . . . 2

Light Microscopy .. . . . . . . . . . . . . 3

Scanning Electron Microscopy . . . . . . . . . . . . 7

Electron Beam Microprobe Analyses . . . . . . . . . . . 12

Discussion ................... 18

Summary . . . . . . . . . . . . . . . . 21

CARBONIZATION AND CONVERSION BREAKAGE OF DUOLITE C-464 LOADED BY

AMMONIA NEUTRAIIZATION METHOD . . . . . . . . . . . . . . . . 21

Chemical, Radiographic, Density, and Screen Analyses . . . 22

Optical Microscopy . . . . . . . . . . . . . . 24

Electron Microprobe ................. 25

Discussion . . . . . . . . . . . . . . . 32

SUMMARY AND RECOMMENDATIONS ................. . . 34

ACKNOWLEDGMENTS . . . . . . . . . . . . . . . . 35

REFERENCES .......................... 35 
HTGR FUEL DEVELOPMENT: INVESTIGATIONS OF BREAKAGES OF URANIUM-LOADED WEAK ACID RESIN MICROSPHERES

J. A. Carpenter, Jr.

\begin{abstract}
During the HTGR fuel development program, a high percentage of uranium-loaded weak acid resin microspheres broke during pneumatic transfer, carbonization, and conversion. One batch had been loaded by the $\mathrm{UO}_{3}$ method; the other by the ammonia neutralization method. To determine the causes of failure, samples of the two failed batches were investigated by optical microscopy, scanning electron microscopy, electron beam microprobe, and other techniques. Causes of failure are postulated and methods are suggested to prevent recurrence of this kind of failure.
\end{abstract}

\title{
INTRODUCTION
}

The technique of using ion-exchange resin microspheres for producing uranium-bearing kernels of coated fissile fuel particles for the HTGR was conceived at ORNL in $1969 .^{1,2}$ Its acceptance has grown so rapidly that it has supplanted the older sol-gel technique and is now the reference process for refabrication. (However, the sol-gel method is still used to produce thorium-bearing fertile particles.)

In the resin-based approach, commercially supplied resin microspheres are brought into contact with a uranyl nitrate solution. The uranyl ion $\left(\mathrm{UO}_{2}{ }^{++}\right.$) exchanges with the cation of the resin (typically $\mathrm{Na}^{+}, \mathrm{H}^{+}$, or $\mathrm{NH}_{4}{ }^{+}$) and becomes part of the polymer structure. The loaded microspheres are dried, then heated in an inert atmosphere to temperatures above $500^{\circ} \mathrm{C}$ to decompose the resin and form a product that consists of fine $\mathrm{UO}_{2}$ particles dispersed in an amorphous carbon matrix. This process is called carbonization.

Then the carbonized particles are heated in an inert atmosphere to . about $1500^{\circ} \mathrm{C}$ to cause the $\mathrm{UO}_{2}$ to react, partially or completely, with the carbon matrix to form kernels of $\mathrm{UC}_{2}$. This process is called conversion. 
The converted kernels are then coated with carbon (and sometimes silicon carbide) to form the fuel particle.

A11 work of this kind at ORNL has been with the cation-exchange type of resin - either the sulfonated, styrene-divinylbenzene cross-1inked, strong. acid resin (SAR), or the carboxylic, acrylic acid-divinylbenzene cross-1inked, weak acid resin (WAR). Both resins produce acceptable kernels, but because of objections to sulfur and low uranium density, development work with SAR was discontinued in late 1973 in favor of WAR. Processes and large-scale equipment have since been developed as prototypes for future hot-cell applications. During this development, large numbers of WAR batches have been loaded, handled, carbonized, and converted. Of these, only two batches tailed during processing. This report detalls our investigation of these two batches and postulates causes of their failure.

We wish to emphasize that this presentation of resin failures is in no way an indictment of the resin-based approach. To the contrary, since only two failures in the course of any development work is an outstanding record, we believe that the resin-based approach is totally viable. Therefore, the reasons for this report are (1) to show that the causes of the failures are known and controllable, (2) to point out the need for close control of certain processes involved in producing and loading the microspheres, and (3) to document the failures in case they recur.

\section{FAILURE OF AMBERLITE IRC-72* DURING CARBONIZATION AND PNEUMATIC TMNEFER}

This batch of Amberlite IRC-72 was loaded via the $\mathrm{UO}_{3}$ method. ${ }^{3}$ Many other batches of this type of resin loaded by this method had been successfully carbonized and converted. At the sompletinn of the first carbonization run with a portion of this batch nearly half the particles were broken. ${ }^{4}$ This failure was particularly disconcerting because the carbonization run was the very first in a new piece of equipment and, consequently, we were uncertain as to whether the failure was caused by the resin or the new unit. Impurity analyses revealed slightly higher

\footnotetext{
${ }^{*}$ Trademark of Rohm and Haas, Co., Philadelphia, Pennsylvania.
} 
silicon $^{5}$ and slightly lower uranium ${ }^{6}$ contents than in other batches. The ramifications of these slight deviations were not obvious.

Subsequently, we tested another portion of this batch in pneumatic transfer experiments. During these tests some of the particles cracked under conditions in which similar microspheres from other batches did not. The cracked pieces were quite abnormal, so whatever the problem, it obviously affected the strength and resilience of the uncarbonized as well as the carbonized resin microspheres.

\section{Light Microscopy}

Examples of resin particles that cracked during the pneumatic transfer tests are shown in Fig. 1. The unusual inner structures of the particles were obvious when compared with particles examined later. The irregularly shaped white central area is surrounded by a yellowish glassy material, which in turn is surrounded by a pale yellow-green translucent shell. The

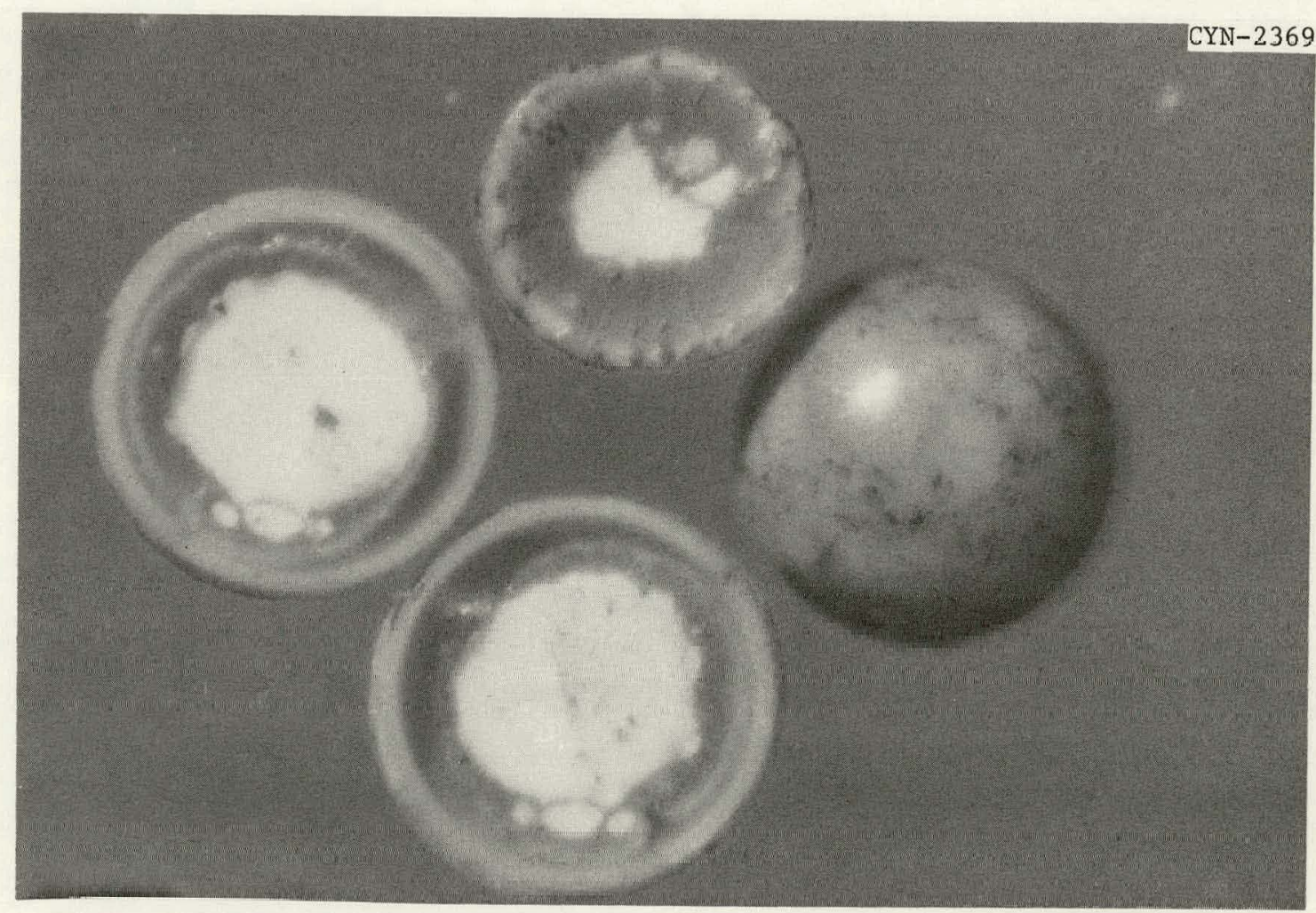

Fig. 1. Uranium-Loaded Amberlite IRC-72 Weak Acid Resin Microsphere Pieces Cracked During Pneumatic Transfer. 60×. Reduced 14.5\%. 
whole is enclosed by a thin glassy rim. (Color versions of these figures are available upon request.) The white color of the central areas is reminiscent of the resin before loading. The black specks on the surfaces of the particles in this and the other figures is flake graphite blended with these particles to reduce static charges.

To ascertain the extent of this unusual inner structure throughout the batch, other particles were selected at random from the batch and cracked open by crushing between the anvil and spindle of a hand-held micrometer caliper. The bits and pieces so produced are shown in Fig. 2. Clearly, the unusual inner structure was not typical of the majority of the particles. Note the apparently clean breaks of some of the glassy material away from the translucent material.

Whole uncrushed microspheres are shown in Fig. 3. Note the darkor color of the three slightly smaller microspheres that are aligned horizontally just above center.

For comparison, we took microspheres from another batch of loaded Amberlite IRC-72 with which no difficulties had been encountered. The only major difference between this good batch and the faulty batch was that the former was loaded by the uranyl nitrate method ${ }^{7}$ (with solvent extraction of nitrate). Some of these particles were deliberately cracked open as before; some of the bits and pieces are shown in Fig. 4, which shows that the translucent material seen in Figs. 1 and 2 is the norm - not the white nor the glassy portions. Comparison of whole microspheres from the normal batch (Fig. 5) with those of the faulty batch (Fig. 3) shows that the three smaller, darker microspheres seen in Fig. 3 are abnormal.

Figure 5 also illustrates a defect often observed in batches of resin microspheres; namely, clumps or clusters of small microspheres attached to the larger ones. The batch shown was shape separated by the vibrating plate technique ${ }^{8}$ which, while adequate for rejecting grossly out-of-round particles, is apparently inefficient in removing those with the small satellites. The satellites seem to be more prevalent in Amberlite IRC-72 resin than in Duolite C-464, ${ }^{*}$ which is discussed later,

\footnotetext{
*Trademark of Diamond-Shamrock, Co., San Francisco, California.
} 


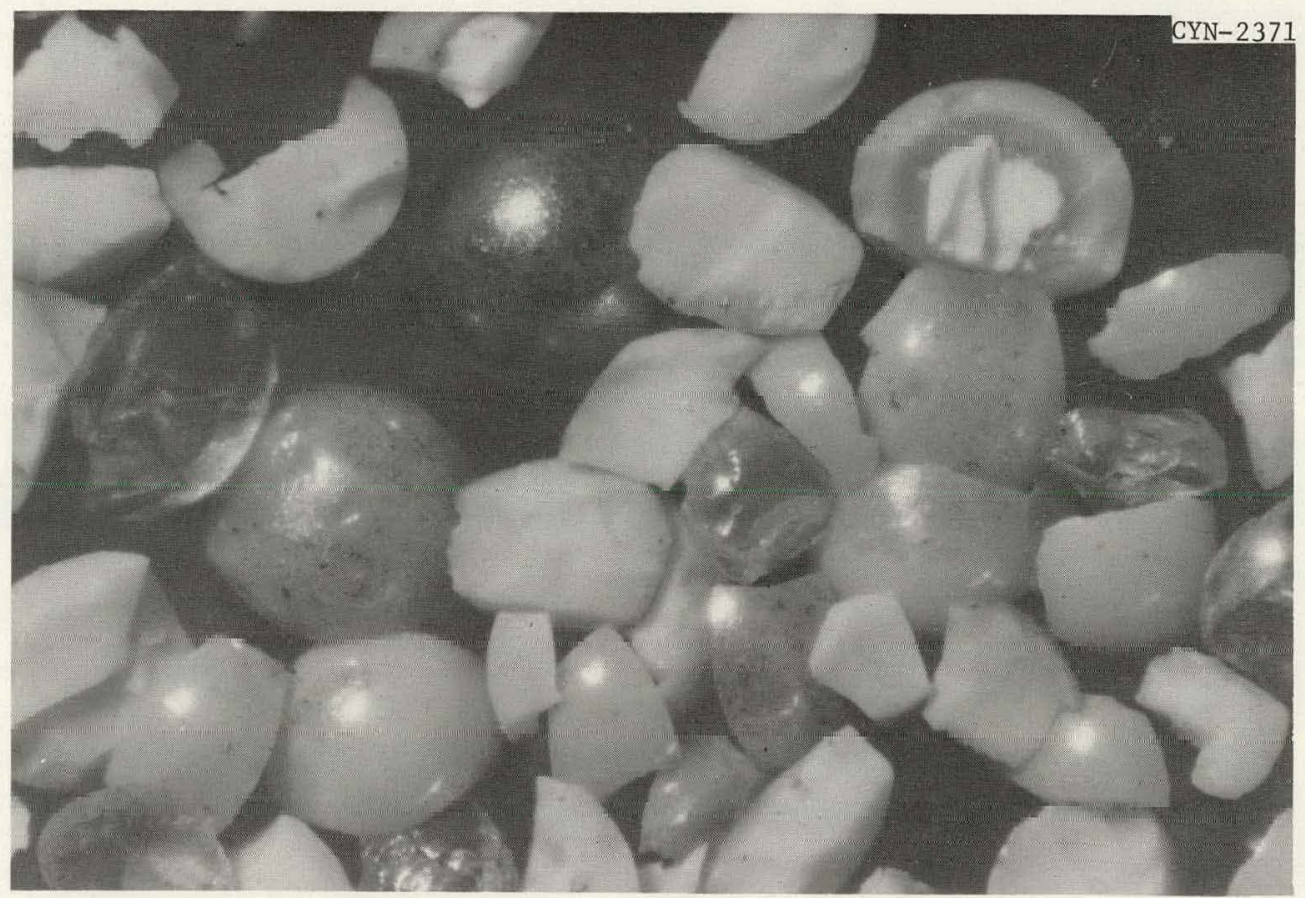

Fig. 2. Bits and Pieces of Uranium-Loaded Amberlite IRC-72 Weak Acid Resin Microspheres Selected at Random from the Same Batch as the Broken Pieces Shown in Fig. 1. These are fragments of deliberately crushed whole microspheres. $60 \times$. Reduced $24 \%$.

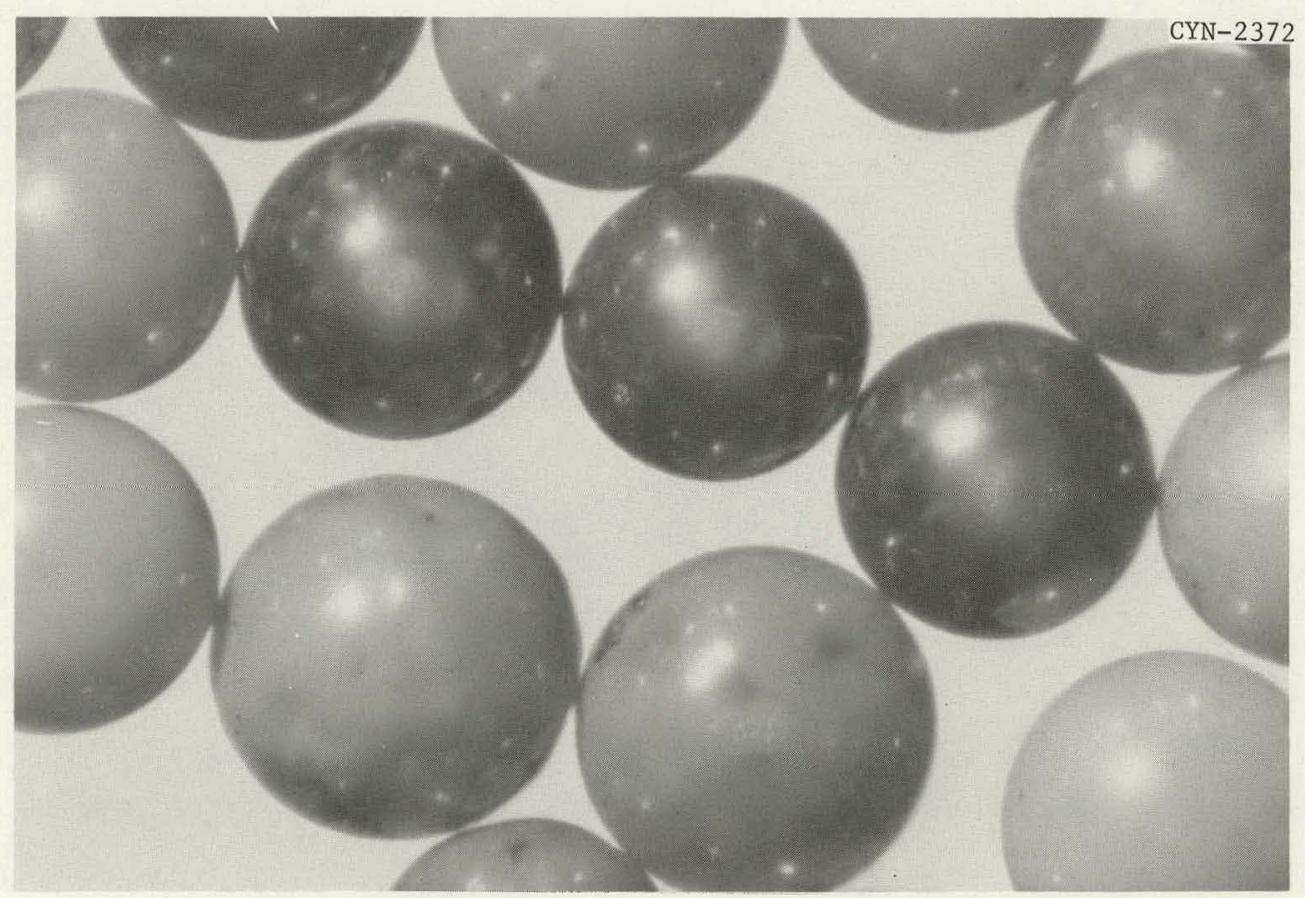

Fig. 3. Whole Uranium-Loaded Amberlite IRC-72 Weak Acid Resin Microspheres Selected at Random from the Same Batch as Those Shown in Figs. 1 and 2. 60×. Reduced $24 \%$. 


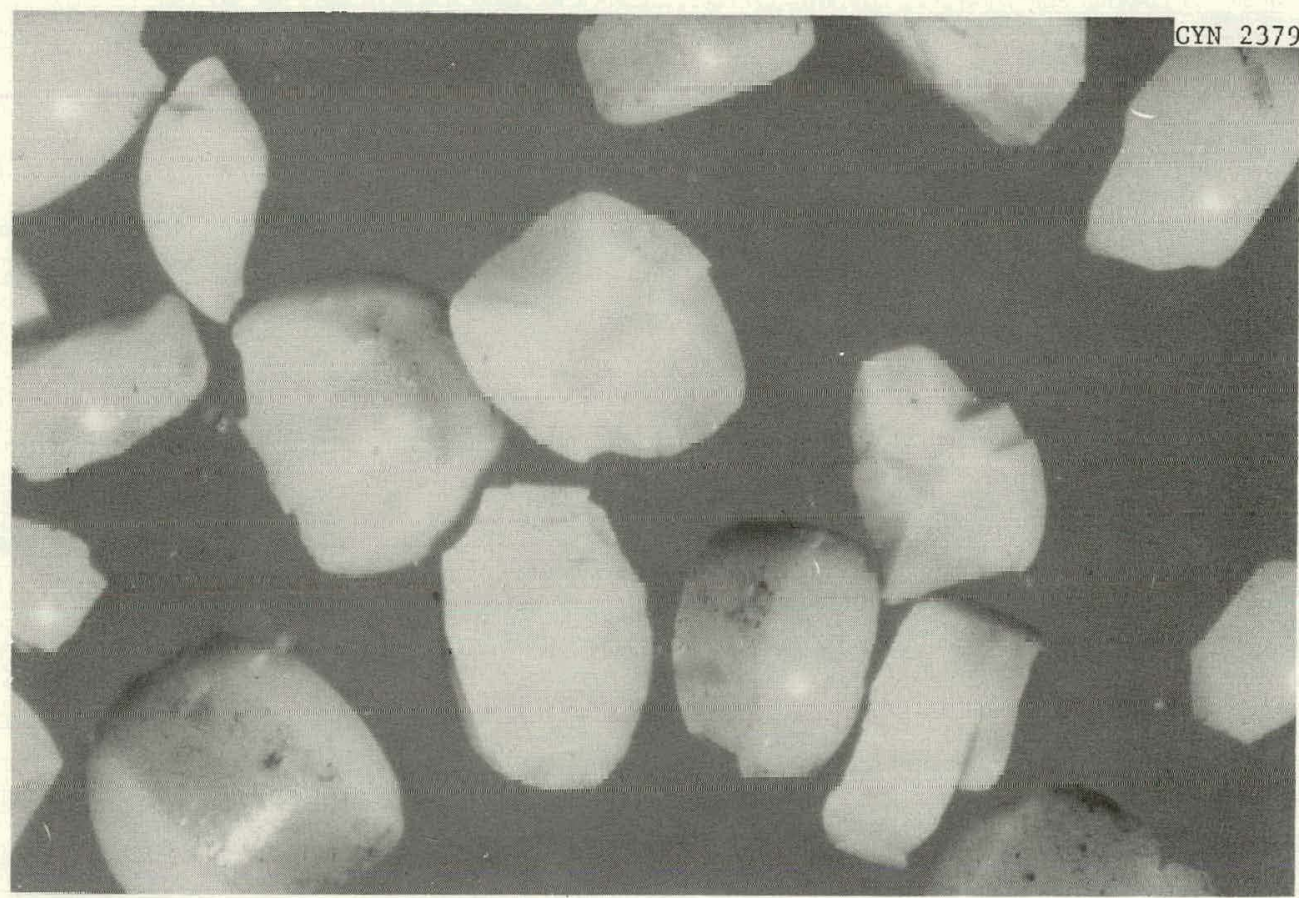

Fig. 4. Bits and Pieces of Uranium-Loaded Amberlite IRC-72 Weak Acid Resin Microspheres Selected at Random from a Normal Batch and Deliberately Crushed. 60x. Reduced $24 \%$.

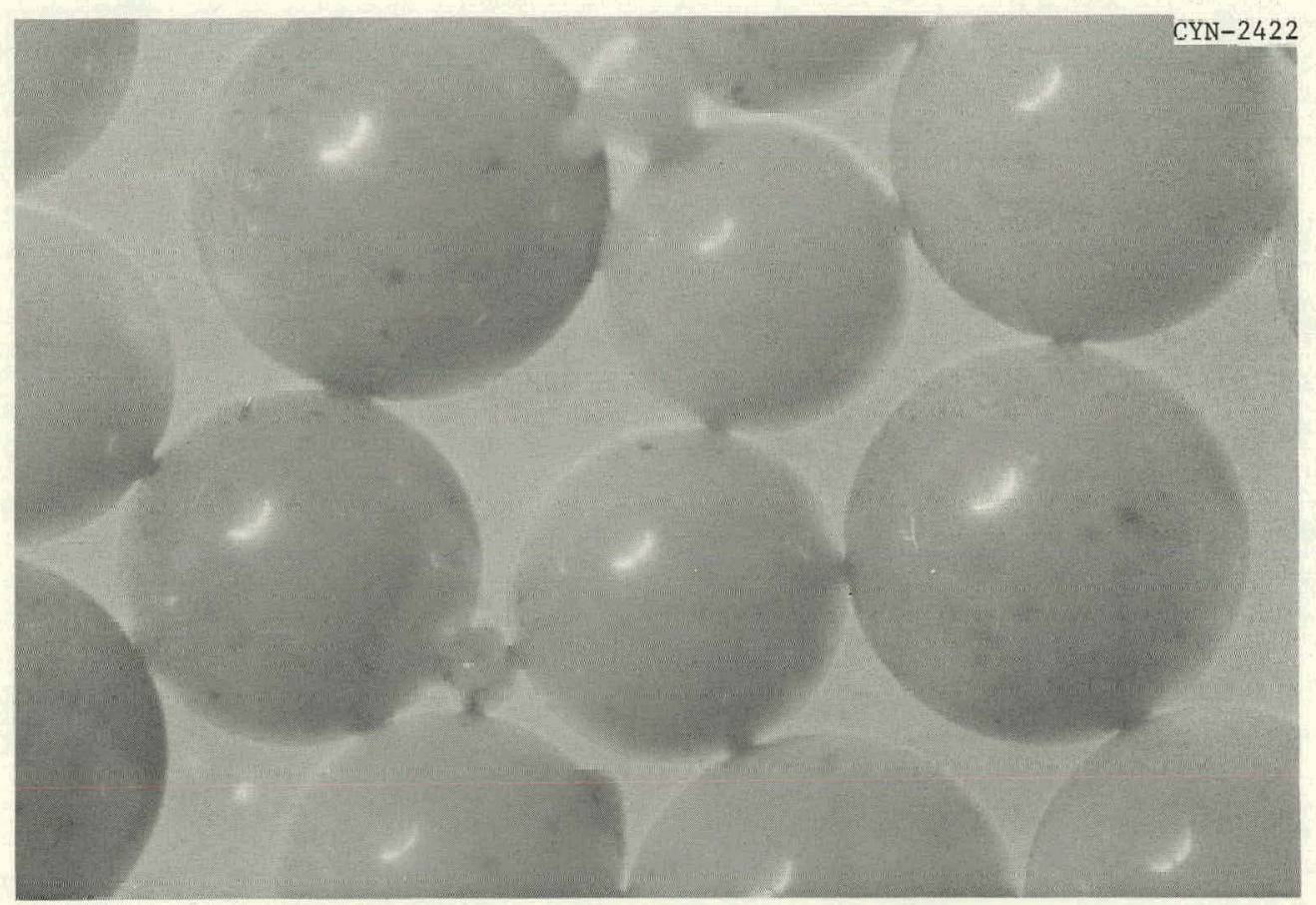

Fig. 5. Whole Uranium-Loaded Amberlite IRC-72 Weak Acid Resin Microspheres Selected at Random from the Same Normal Batch as the Pieces Shown in Fig. 4. 60x. Reduced $24 \%$. 


\section{Scanning Electron Microscopy}

The white color of the material in the center of the particles broken in pneumatic transfer (Figs. 1 and 2) suggested that perhaps it was not loaded. To verify this, some of the broken particles were analyzed as-is in a scanning electron microscope (SEM) equipped with a nondispersive $\mathrm{x}-\mathrm{ray}$ fluorescence detector. A low-magnification view of some of the broken pieces is shown in Fig. 6. Close-up views of one piece with a peculiar kidney-shaped center are shown in Fig. 7. Photographs of x-ray spectra from various points on the particle fragment are shown in Fig. 8. Figure 9 is a view of another fragment, and Fig. 10 is a photograph of its spectra.

Figure 6 shows that the fracture of the particles that broke during the pneumatic transfer was essentially bimodal, characterized by an outer region in which the fracture surface is smooth and almost perfectly planar and a central region where the surface is wrinkled. The proportion of the two regions varies from particle to particle, but careful inspection does show some of each type in all the pieces. The piece in the center toward

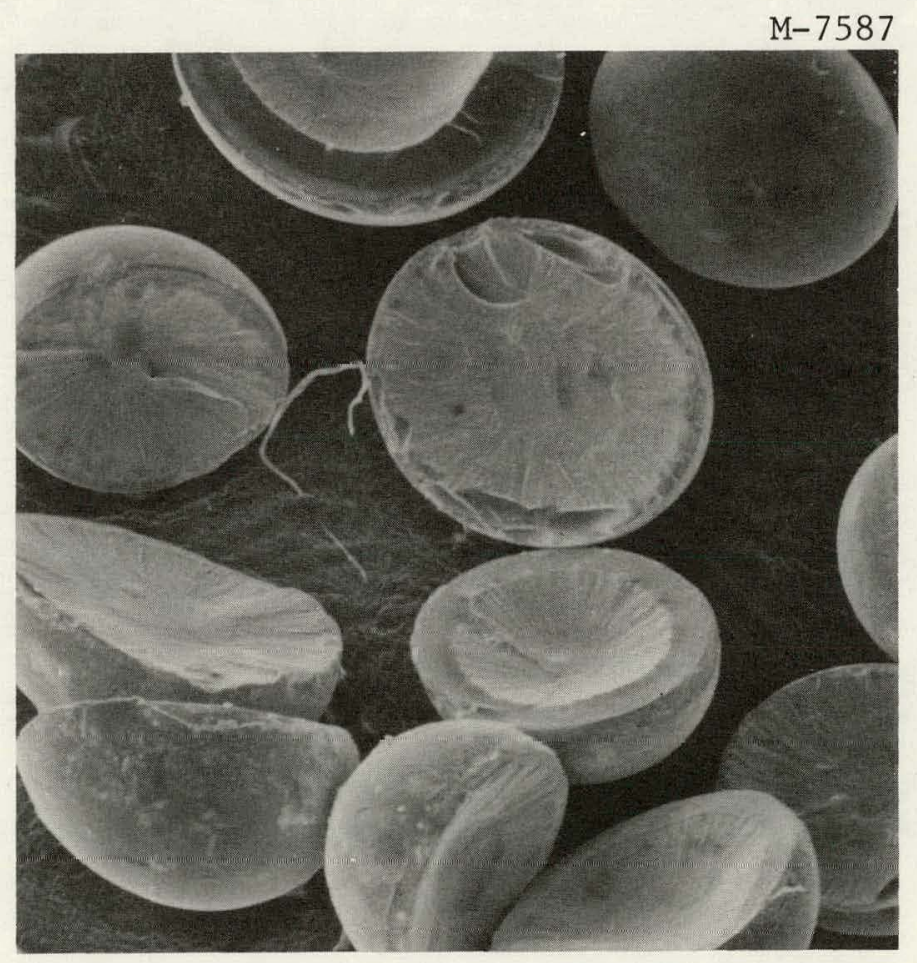

Fig. 6. Scaming Electron Microscope (SEM) Phntomicrograph of Pieces of Uranium-Loaded Amberlite IRC-72 Weak Acid Resin Broken During Pneumatic Transfer. 55×. Compare with Fig. 1. 

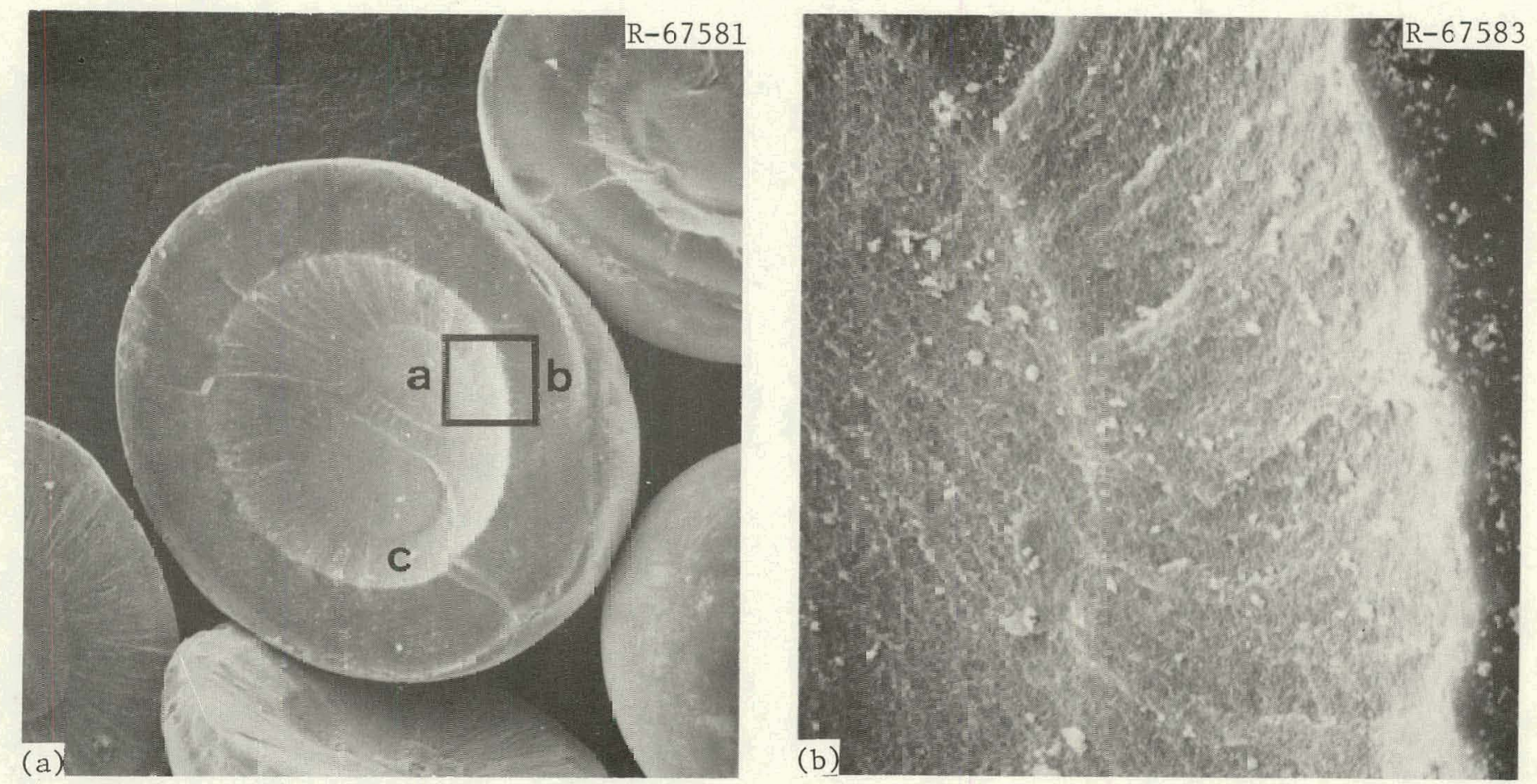

Fig. 7. SEM Photomicrographs of a Piəze of Uranium-Loaded Arberlite IRC-7£ Weak Acid Resin Microsphere Broken During Presnatic Fransfer. The points on (a) indicate where x-ray spectra were obtained. The letters on (a) indicate points ccrrespozding to the spectra of Fig. 8. The box window on (a) indicates the area viewed in (b). (a) 100x. (b) $1000 \times$. 

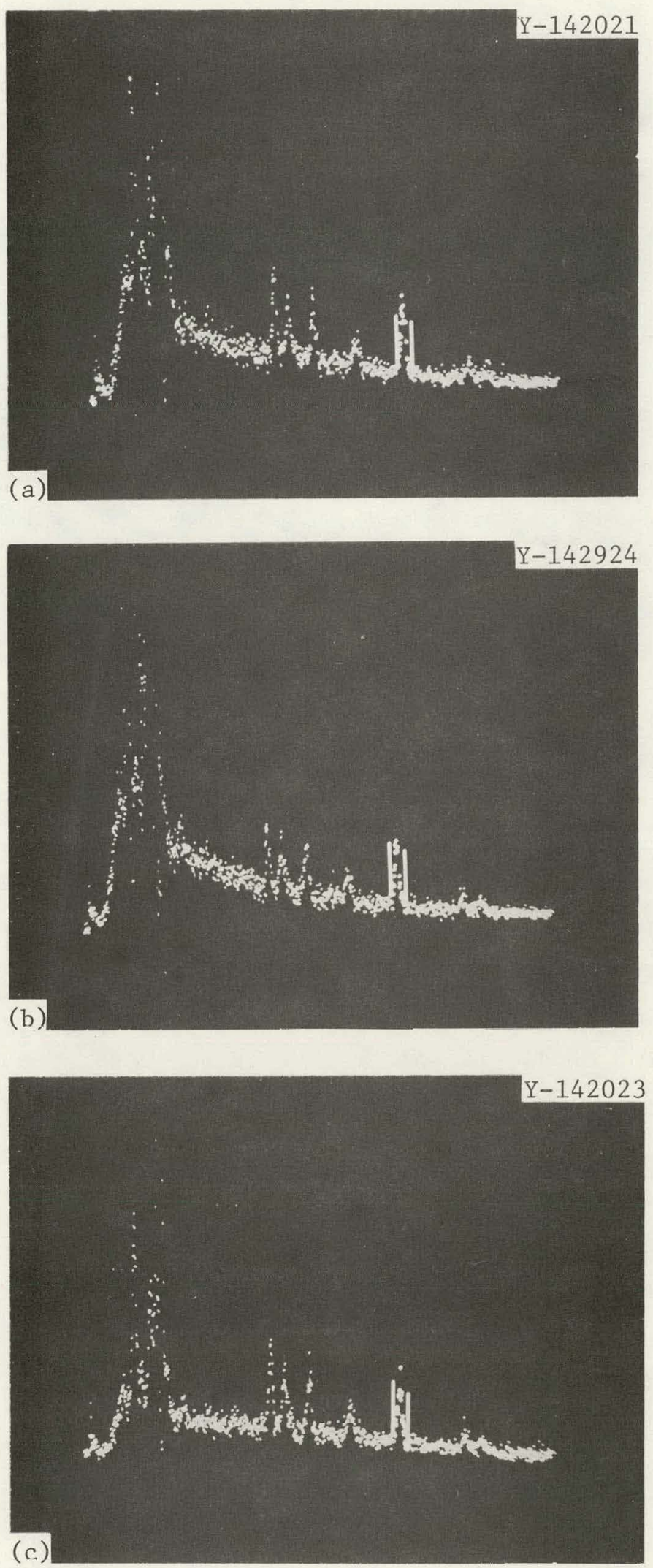

Fig. 8. SEM X-Ray Spectra from the Lettered Points on Fig. 7(a). The bracketed line is uranium L-alpha. The others are caused by the instrument, not the specimen. 


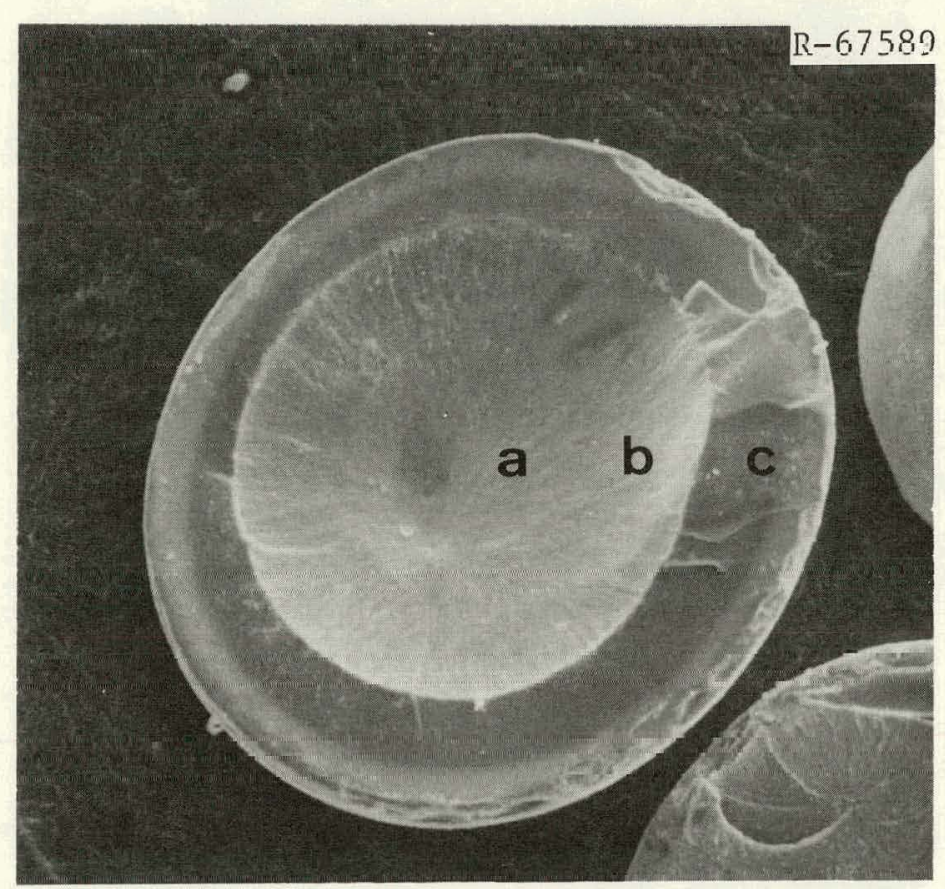

Fig. 9. SEM Photomicrograph of a Piece of Uranium-Loaded Amberlite IRC-72 Weak Acid Resin Microsphere Broken During Pneumatic Transfer. The spots indicate points where the $x$-ray spectra shown in Fig. 10 were taken. $100 \times$.

the upper right, for example, has only a very small outer region compared with the one just below it or the one above it to the left. Notice too that the center region of the pieces appears to be collapsed, giving some of the pieces a shape resembling a cantaloupe half. It is not clear whether this is a region of ductile material that was under tension and collapsed inward when the microsphere broke or if it is perhaps an interface between a glassy region and a white central core that has been pulled out.

Figure 7 shows closeup detail of such a particle. This one had the distinct white central areas seen in the pieces in Figs. 1 and 2. This white material appears in the SEM photomicrograph of Fig. 7 (a) as the two kidney-shaped areas in the center. The material surrounding these areas is yellowish in color as is the smoother outer region. The window superimposed on Fig. 7(a) identifies the area viewed in Fig. 7(b). The letters on Fig. $7(a)$ indicate the points where $x$-ray spectra were taken, and the corresponding spectra are shown in Fig. 8(a)-(c). The spectral line of interest, U L-alpha, is shown bracketed in Figs. 8(a)-(c). The remainder of the lines are due to components of the SEM, not the specimen. From 

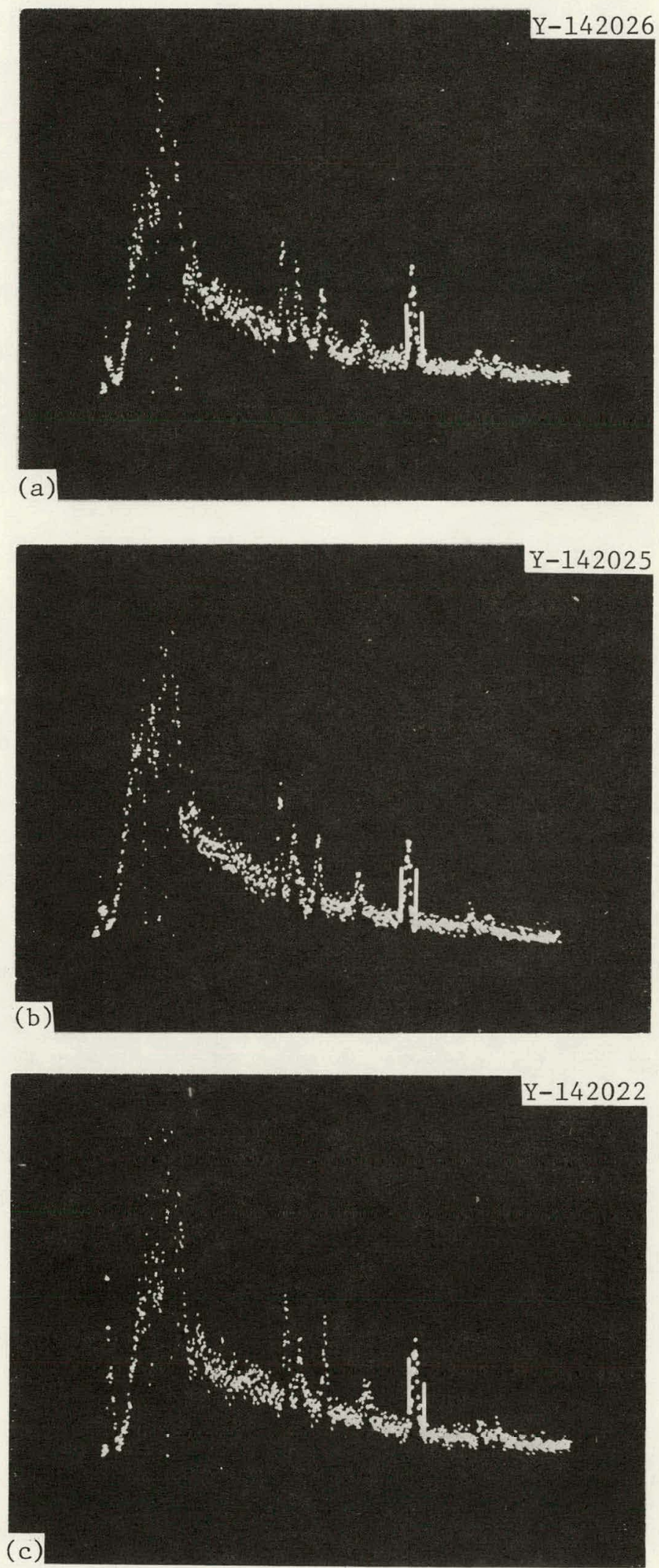

Fig. 10. SEM X-Ray Spectra from the Spots Indicated on Fig. 9. The bracketed line is uranium L-alpha. The others are caused by the instrument, not the specimen. 
Figs. 8(a)-(c) it appears that all points measured, including the white material, had about the same uranium content.

Figure 9 shows an example of a piece with a thick, smoothly broken outer region, but no white area in the center. Spectra corresponding to the points superimposed on Fig. 9 are presented in Figs. 10(a)-(c). The intensities of the bracketed $U \mathrm{~L}$-alpha confirm the previous findings that all points have essentially the same uranium contents. In view of the electron microprobe results that follow, this result was probably not entirely correct. Unfortunately, no spectra were taken from the lighter outer portion of the smoothly broken region in Fig. 9.

\section{Electron Ream Microprobe Analyses}

The SEM results, which indicated that all points of the pieces broken during pneumatic transfer had essentially the same uranium concentration, were surprising. To pursue this further, whole microspheres were chosen at random from the parent batch, metallographically mounted, sectioned, polished, and investigated by means of an electron beam microprobe. Bright field and polarized light optical photomicrographs of several microspheres taken during these analyses are shown in Figs. 11 and 12, respectively, and $\mathrm{x}$-ray scans and optical photomicrographs of tour particles are presented in Figs. 13 to 16 . The $x$-ray line in all the scans is U M-alpha.

The particle in the upper rights of Figs. 11 and 12 is the type generally found among those that broke during the pneumatic transfer (Fig. 1). The microprobe scan (Fig. 13) confirms that the white material in the center does indeed have essentially the same uranium content as the yellowish glassy material surrounding it. However, it also shows that the yellowish translucent material toward the outer portion of the piece contains more uranium. This would not have been known without microprobe analysis.

The particle in the lower right of Figs. 11 and 12 is a type not generally seen in those that broke during pneumatic transfer but may be the precursor of the half cantaloupe-shaped particle in Figs. 7 and 9 . It is characterized by a white circular center surrounded by yellowish glassy material and then yellowish translucent material. Close inspection of 


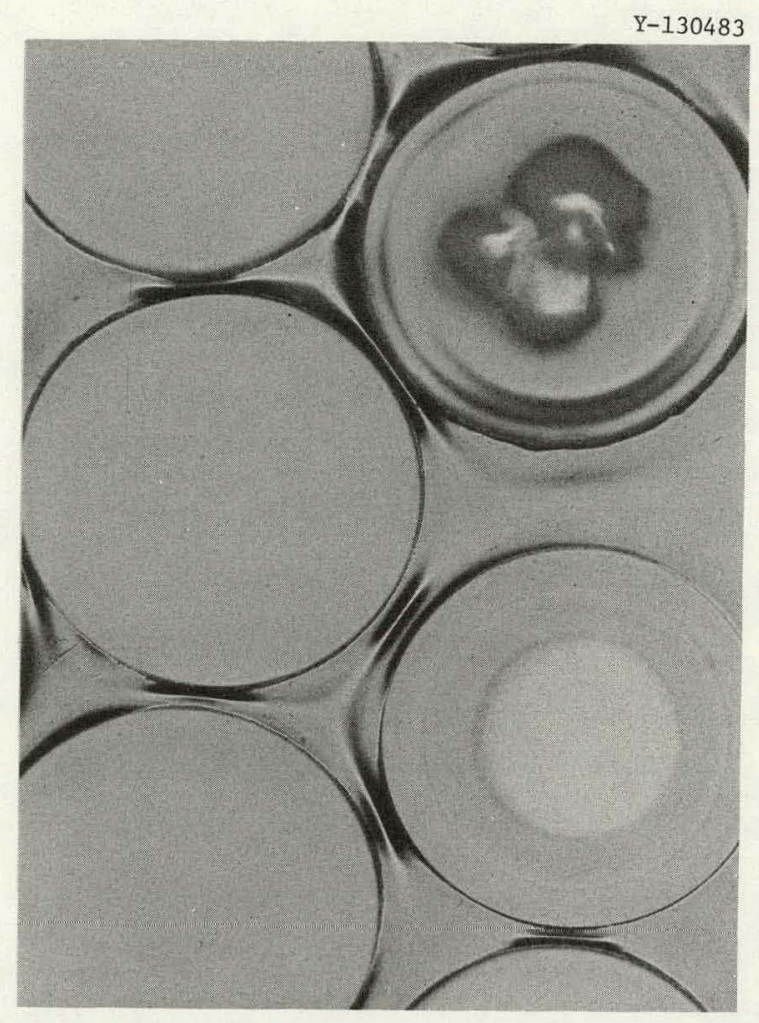

Fig. 11. Uranium-Loaded Amberlite IRC-72 Weak Acid Resin Microspheres Selected at Random from the Batch that Exhibited Breakage During Pneumatic Transfer, Carbonization, and Conversion. These particles have been mounted metallographically, sectioned, and polished for electron beam microprobe analyses. 100x. Reduced 33\%.

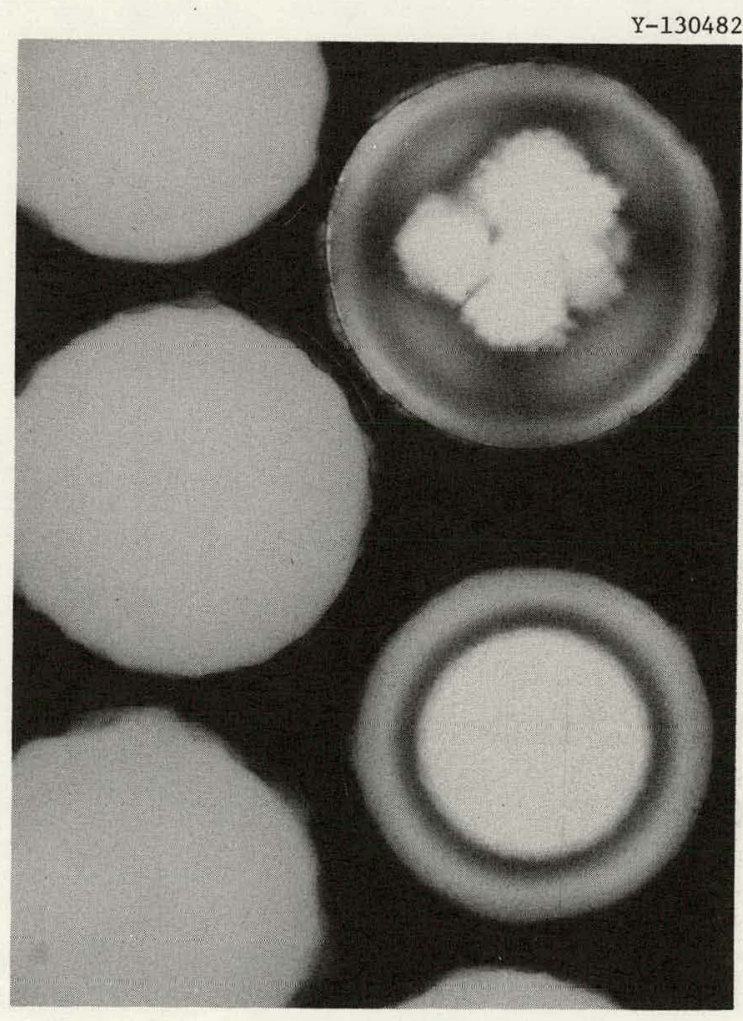

Fig. 12. Same View as Fig. 11 but Under Polarized Light. 100×. Reduced 33\%. 


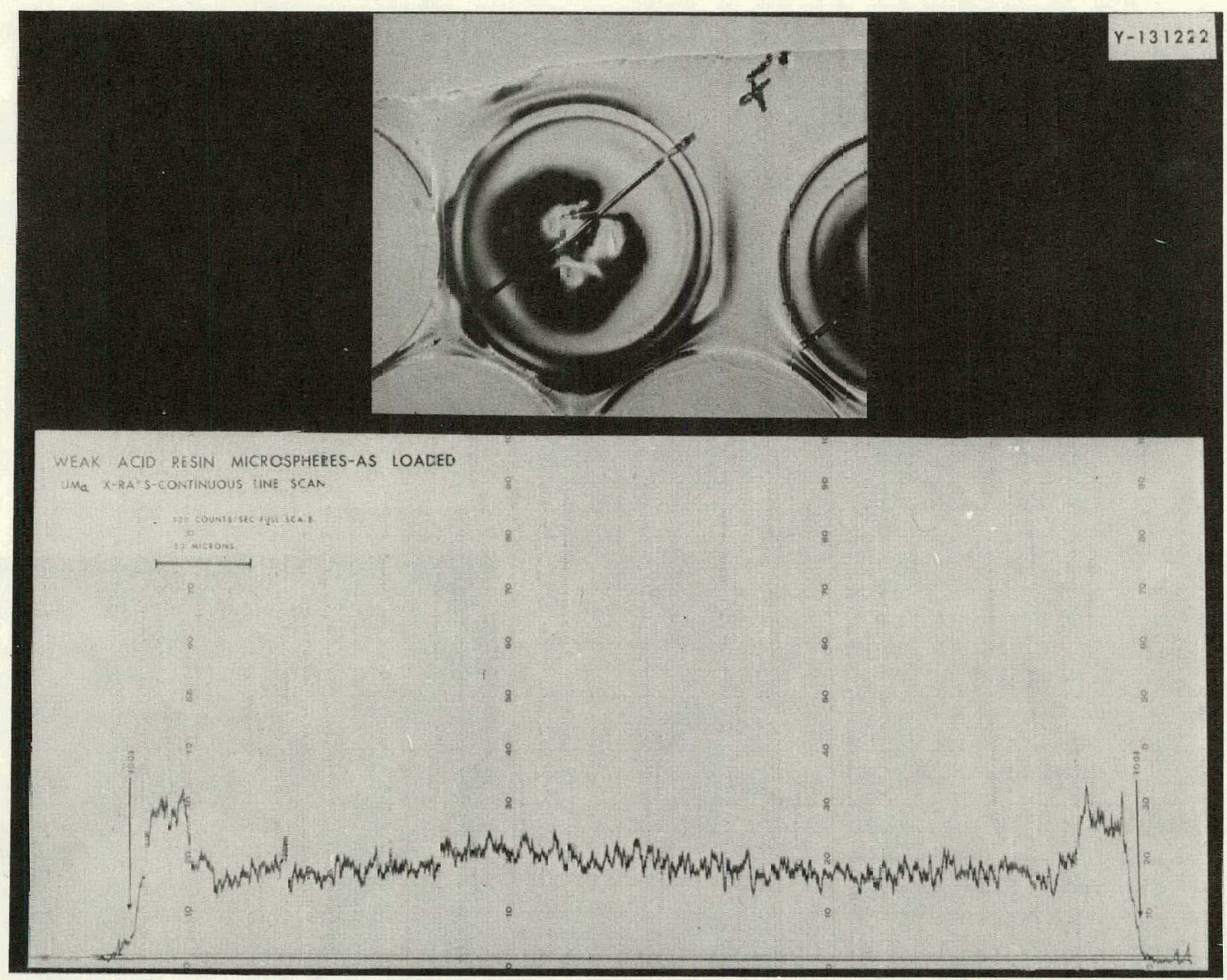

Fig. 13. Photomicrograph and Electron Eeam Microprcbe Scan of the Eross-Section oz a Urani.um-Ioaded Amberlite IRC-72 Weak Acid Resir. Microsphere from the Batch that Exhibit d Breakage During Pneumatic Transfer, Carbonization, and Conversion. This is the type of particle tiat broke during pneumatic transfer. $100 \times$. Reduced $32 \%$. 


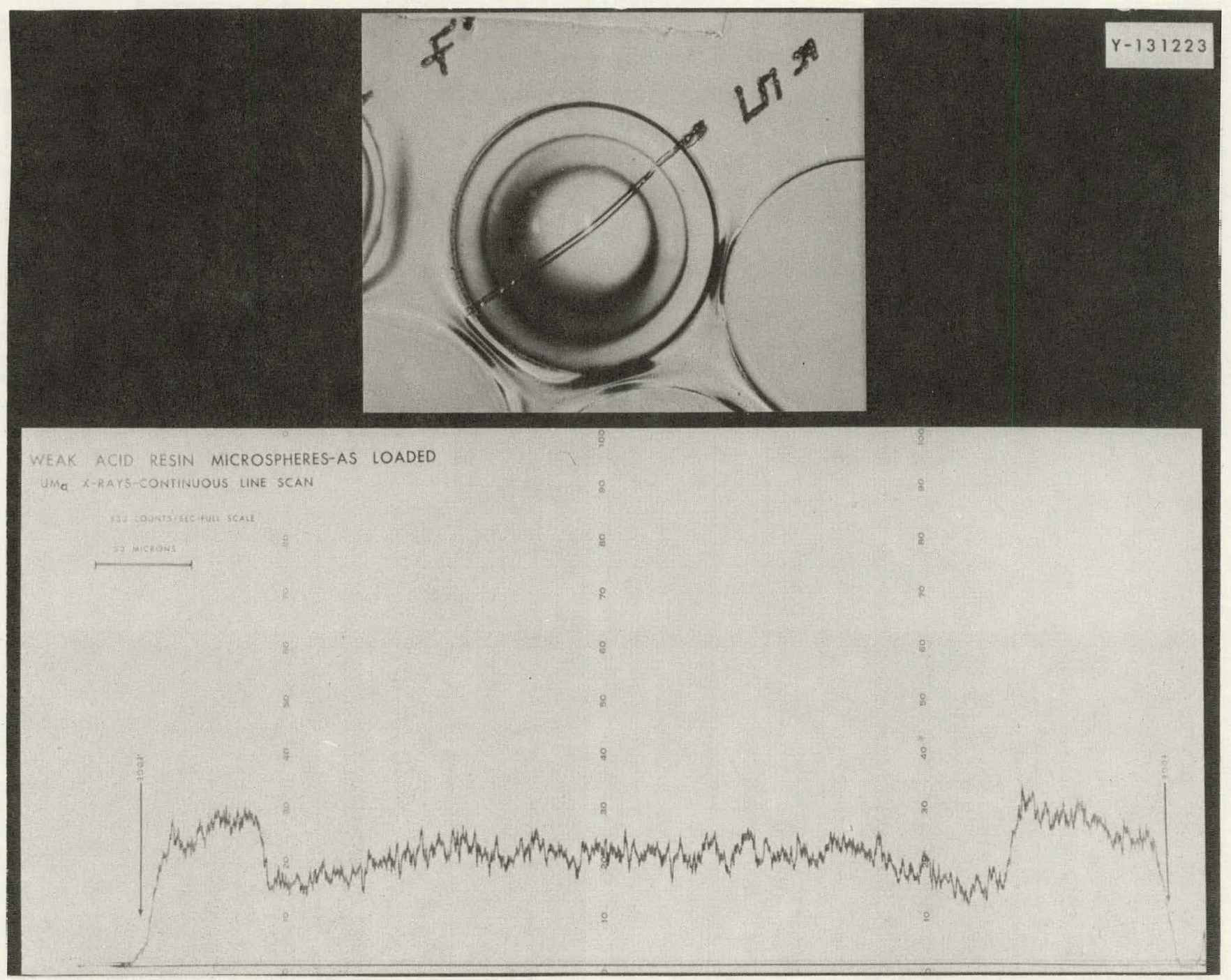

Fig. 14. Photomicrograph and Electron Beam Microprobe Scan of the Cross-Section of a Uranium-Loaded Amberlite IZC-72 Weak Acid Resin Microsphere from the Batch that Exhibited Breakage During Pne-dmatic Transfer, Carbonization, and Conversion. 100×. Reduced $32 \%$. 


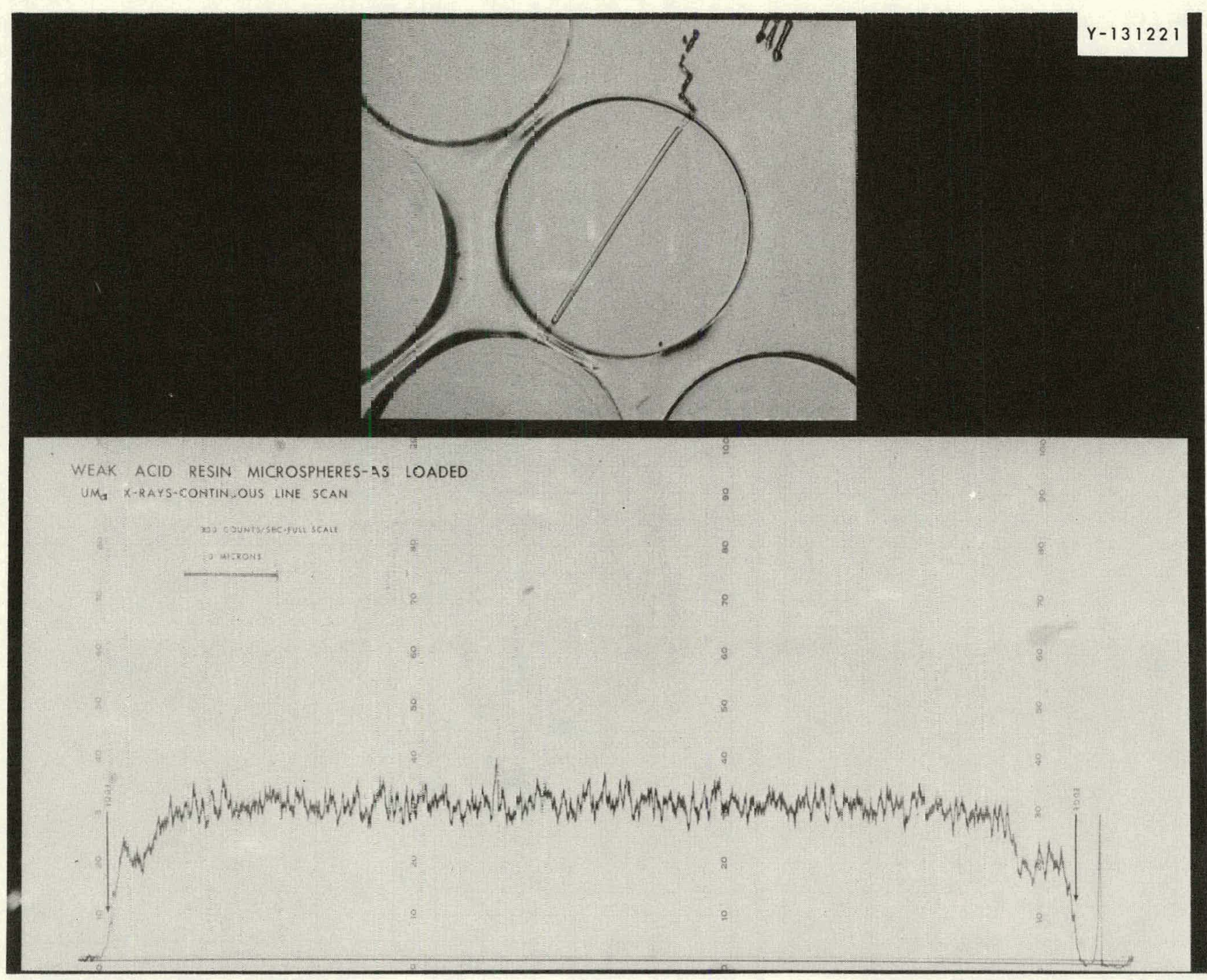

Fig. 15. Photomicrograph and Electron Beam Microprobe Scan of the Cross-Section of a "Normal" Uranium-Loaded Amberlite -RC-72 Weak Acid Resin Vicrosphere from the Batch that Exhibited Breakage During Pneumatic Transfer, Carbonization, and Conversior. 100x. Reduced 32\%. 


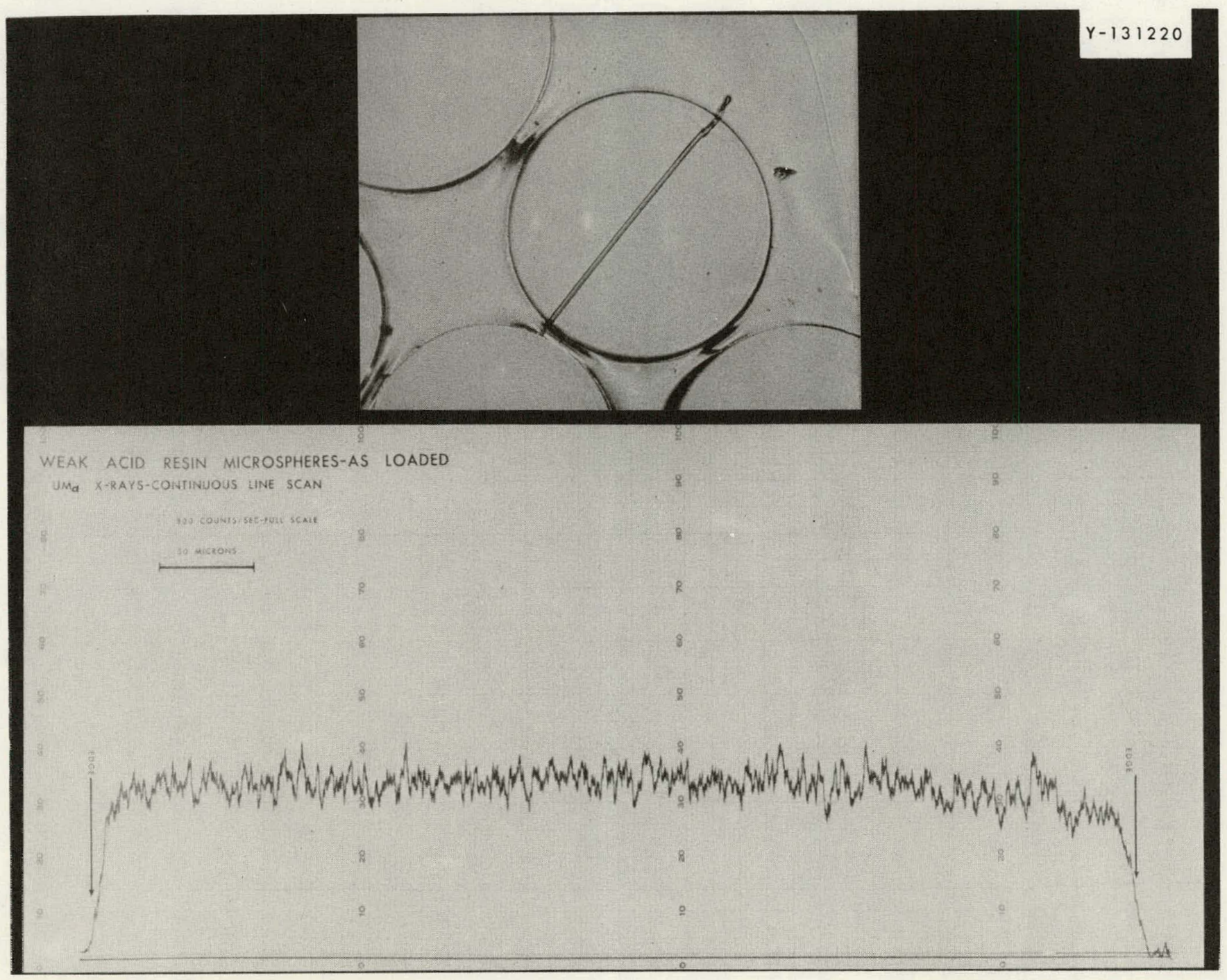

Fig. 16. Photomicrograph and Electron Beam Microprobe Scan of the Cross-Section of a "Normal" Uranium-Loaded Amberlite IRC-72 Weak Acid Resin Microsphere from the Batch that Exhibited Breakage During Pneumatic Transfer, Carbonization, and Conversion. 100x. Reduced 32\%. 
Figs. 11 and 12 shows that this particle also has a thin outer shell of material, which appears similar to the glassy material, under polarized light (Fig. 12), only darker. The microprobe scan of this particle (Fig. 14) shows that the white center and the glassy material around it have lower uranium concentrations than the outer translucent material. The thin outer shell of glassy material seems to have about the same uranium concentration (perhaps a bit less) as the translucent material.

Inspection of the "normal" particles in polarized light (Fig. 12) readily reveals that even these have the thin outer shell of glassy material that is barely discernible in optical photomicrographs (Figs. 15 and 16). The scan (Fig. 15) indicates a lower concentration in the outer shell than in the inner translucent region. Un the other hand, the scan in Fig. 16 suggests the outer shell in that case has about the same concentration as the center.

\section{Discussion}

There are two major steps in the production of these uranium-bearing resin microspheres; formation of the microspheres and their subsequent loading. Two observations suggest that the malfunction in this instance did not occur in the loading step. First, the very sharp drop in concentration between the translucent and the glassy material, as observed in the microprobe scans of Figs. 13 and 14, would not be expected to result from a loading error. Instead, a more gradual change would be likely. Second, the fact that not all microspheres, not even the majority, exhibited the intra-microsphere concentration differences also seems to rule out a loading error that would probably affect all particles in the batch more or less the same. It should be pointed out, however, that nonuniform or "shell" loading, in which an outer region of high uranium borders a center of no or reduced uranium, has been produced in Amberlite IRC-72 microspheres by the $\mathrm{UO}_{3}$ method, but only with ammonium- or sodiumform resin. ${ }^{9}$

A more likely explanation is some error in the manufacture of the resin, probably overheating. Amberlite IRC-72 is a macroreticular resin, ${ }^{10}$ which means that the microsphere is an agglomerate of even smaller beads 
(on the order of a micrometer in diameter) composed of a polymer gel. There are, therefore, two types and sizes of pores. One type, referred to as the micropores, is within the polymer gel beads and consists of void spaces between the polymer molecules. These are on the order of about $2 \mathrm{~nm}$ in size. The second type is void spaces between the small gel beads. These voids, termed macropores, are on the order of several tens of nanometers in size. These beads are brought together in a controlled-temperature process to form the microsphere. An over-temperature condition may have occurred during the process for some of the particles. ${ }^{11}$ The glassy material probably represents the most affected material; the translucent material, the least affected; and the white central material, intermediate.

Given this tenet, we postulate the following reasons for failure of the resin. The macroporosity of the glassy material was probably reduced to near zero, hence its transparency. The microporosity would be affected as well; consequently, although the total number of potential exchange sites may not have been affected greatly, the ease of loading them may have been affected due to steric hindrance or "shielding" effects. Therefore, loading on this material would be reduced, as observed. The white material may be beads with surfaces closed by, possibly, flash heating, so the beads could not load and retained their white color as a result. The uranium in this area, if not exchanged into the resin, would likely be deposited in the macropores and, because these are sma11, would not contribute much coloring. The fact that the concentration in the white material is the same as that in the glassy material is probably because the glassy material surrounds the white and could control the kinetics of solution infiltration into the bead and the final chemical equilibria within it:

The yellowish translucent material, then, is a close-to-normal' situation. There, macroporosity and microporosity are essentially unaffected and loading is normal. The outer layer is probably not continuous, since the yellowish translucent material is sometimes seen inside the thin outer layer that has a lower concentration. The observation that the outer layer can sometimes have a reduced concentration and sometimes not, 
could indicate that steric hindrance effects on the loading capacity can vary despite the loss of macroporosity.

Breakage of the microspheres during pneumatic transfer probably resulted from the presence of significant quantities of the glassy material. This is clear from Fig. 1, which shows no pieces from normal microspheres (such as seen in Figs. 15 and 16), which contain little of the glassy material except for the thin outer layer. Evidently, the substantial quantities of the glassy material reduced the resilience of the microspheres and made them brittle, so they split.

The causes of the failures during carbonization and conversion may have been more subtle. Although the type of microsphere with substantial quantities of glassy material undoubtedly broke during carbonization and conversion, the numbers of such particles in the batch was not sufficient to account for the $30-50 \%$ failure rate observed after carbonization and conversion. A more extensive abnormality must be suspected, specifically, the thin outer layer of glassy material present on many of the "normal" microspheres. Such material, being initially more dense, would be expected to shrink at a rate different from the normal resin material within it. As a result, stresses could break even some of the normal microspheres.

This batch of resin was the combination of six loading runs, all of which used the same parent supply of unloaded resin supplied as a "lot" by the manufacturer. Other portions of this parent lot of unloaded resin were loaded with no apparent difficulties, a fact which suggests that the abnormalities observed were perhaps due to some malfunction in one of the loading runs. Two steps in which such malfunctions could occur are the conversion of the resin from the as-supplied sodium-form to the hydrogen-form before loading or the drying step after loading. In conversion, the resin could have been contacted with too-concentrated nitric acid. In drying, it could have been heated too long at a too-high temperature.

Certainly, these possibilities camiot be ruled uut, but it is difficult to imagine a scheme whereby these or any of the steps in loading could produce the white centers or the interior glassy material. A resin lot usually comprises several resin production runs and it is quite possible 
that the abnormal particles observed in this batch were the result of a faulty production run. Unfortunately, the unloaded resin lot was not inspected nor were archives kept, so it is impossible to ascertain whether or not the structural abnormalities were present in some of the beads before loading. This points out that quality control tests of the unloaded resin received from the manufacturer would be in order for large-scale HTGR fuel refabrication plants and for development programs.

Summary

1. The structure of the particles that broke during pneumatic transfer was a white central area surrounded by glassy material, then a translucent material, and a thin glassy outer shell.

2. The white material and the glassy material surrounding it had about the same uranium content, which was lower than that in the translucent material.

3. The uranium concentration in the thin glassy outer shell was sometimes typical of the white and sometimes typical of the translucent material.

4. The presence of the glassy material probably indicates that the problem in the batch stemmed not from a malfunction during loading, but from an error in the manufacture of the microsphere itself; specifically, overheating.

5. The failure of the resin microspheres in pneumatic transfer was probably due to excessive quantities of glassy matcrial.

6. The more extensive breakage during carbonization and conversion may have been associated with the small amount of glassy material in the thin outer shell.

\section{CARBONIZATION AND CONVERSION BREAKAGE OF DUOLITE C-464 LOADED BY AMMONIA NEUTRALIZATION METHOD}

In April 1975, the General Atomic Company sent to ORNL a batch of Duolite $\mathrm{C}-464$ resin that had been loaded by ammonia neutralization. ${ }^{12}$ This batch was from the early stages in the development of the method. Sticking of the bed to the furnace walls had been experienced during carbonization and conversion, and ORNL was asked to carbonize and convert 
some in the 5-in. diameter graphite muffle to see if a similar problem occurred. 'l'his we did with little or no difficulty. The only problem was an abnormally high degree of broken particles in the converted product, so we analyzed the resin to determine possible causes of the breakage.

Chemical, Radiographic, Density, and Screen Analyses

We obtained standard chemical, radiographic, and density data for the batch in both resin and converted forms. To determine a measure of broken material, we performed special screen analyses of whole spheres, which enabled us to establish the percentage of material above and below the minimum size measured by radiography. The chemical, radiographic, and density data are presented in Table 1. A print of the radiograph for

Table 1. Comparison of Data for Carbonization and Conversion of Loaded via Three Methods Duolite and Amberlite Resins ${ }^{\text {, }}$

\begin{tabular}{|c|c|c|c|c|}
\hline $\begin{array}{l}\text { Resin: } \\
\text { Loading Method: } \\
\text { Run: }\end{array}$ & $\begin{array}{l}\text { Duolite } \\
\text { C-464 } \\
\mathrm{NH}_{3} \\
\text { V54 }\end{array}$ & $\begin{array}{l}\text { Duolite } \\
\text { C-464 } \\
\mathrm{UO}_{3} \\
\mathrm{~V} 48\end{array}$ & $\begin{array}{l}\text { Amberlite } \\
\text { IRC-72 } \\
\text { U0 } \\
\text { V55 }\end{array}$ & $\begin{array}{l}\text { Amberlite } \\
\text { IRC } \div 72 \\
\mathrm{UO}_{2}\left(\mathrm{NO}_{3}\right)_{2} \mathrm{C} \\
\mathrm{V} 47\end{array}$ \\
\hline \multicolumn{5}{|c|}{ Before Carbonization and Conversion } \\
\hline $\begin{array}{l}\mathrm{U} \text {, wt \% of undried resin } \\
\text { Water, wt\% of undried resin } \\
1, \text { wt } \% \text { of resin dried at } 110^{\circ} \mathrm{C} \\
\text { Radiograph size of undried resin, } \mu \mathrm{m}\end{array}$ & $\begin{array}{l}45.5 \\
10.79 \\
51.0 \\
490\end{array}$ & $\begin{array}{l}46.0 \\
1.72 \\
46.8 \\
530 \\
\text { (assumed) }\end{array}$ & $\begin{array}{l}43.5 \\
9.24 \\
47.9 \\
530 \\
\text { (assumed) }\end{array}$ & $\begin{array}{l}46.3 \\
3.78 \\
48.0 \\
524\end{array}$ \\
\hline \multicolumn{5}{|c|}{ After Carbonization and Conversion } \\
\hline $\begin{array}{l}\text { U, wt\% } \\
\text { C, wt\% } \\
0 \text {, wt\% (by analysis) } \\
0 \text {, wt\% (by difference) } \\
\% \text { conversion (by analysis) } \\
\% \text { conversinn (hy differenre) } \\
\% \text { excess carbon (by analysis) } \\
\lambda \text { excese carbon (by difterence) } \\
\text { Radiograph size, } \mu m \\
\% \text { diametral shrinkage } \\
\text { Density, } \mathrm{Mg} / \mathrm{m}^{3}\end{array}$ & $\begin{array}{l}82.6 \\
14.28 \\
3.94 \\
3.12 \\
64.5 \\
71.9 \\
62.4 \\
58.1 \\
315 \\
35.7 \\
3.20\end{array}$ & $\begin{array}{l}80.595 \\
16.94 \\
3.51 \\
2.465 \\
67.6 \\
77.3 \\
67.5 \\
62.9 \\
382 \\
27.9 \\
2.59\end{array}$ & $\begin{array}{l}81.935 \\
16.14 \\
2.93 \\
1.925 \\
73.4 \\
82.5 \\
62.4 \\
57.8 \\
339 \\
36.0 \\
3.38\end{array}$ & $\begin{array}{l}82.14 \\
15.925 \\
2.87 \\
1.935 \\
74.0 \\
82.5 \\
61.5 \\
57.1 \\
354 \\
32.4 \\
3.2 .3\end{array}$ \\
\hline
\end{tabular}

\footnotetext{
a Furnace: 5-in. diam multipurpose with $30^{\circ}$ cone and graphite muffle. Heat cycle: resin dried at $110^{\circ} \mathrm{C}$ in air at least $16 \mathrm{hr}$, heated in argon to $600^{\circ} \mathrm{C}$ at $2^{\circ} \mathrm{C} / \mathrm{min}$, held $15 \mathrm{~min}$, heated in argon to $1712^{\circ} \mathrm{C}$ at about $240^{\circ} \mathrm{C} / \mathrm{min}$, and held for $30 \mathrm{~min}$. Argon flow constant at 1 scfm.

${ }^{\mathrm{b}}$ The Duolite resin loaded by ammonia neutralization (run V54) was sent by GA to ORNL for testing.

${ }^{c}$ With solvent extraction of nitrate.
} 
the converted product is shown in Fig. 17. In obtaining the size of the converted material from this radiograph, only whole particles were read. The high percentage of broken bits and pieces of particles is obvious. The results of the screen analyses (Table 2) show that about $10 \%$ of the total weight of the converted batch consisted of pieces that would pass a screen opening smaller than the smallest whole particle seen in the radiograph. By contrast, similar screen analyses of converted ORNL resin typically show less than $1 \%$, as shown in Table 2, run V48, data for which were also given in Table 1.

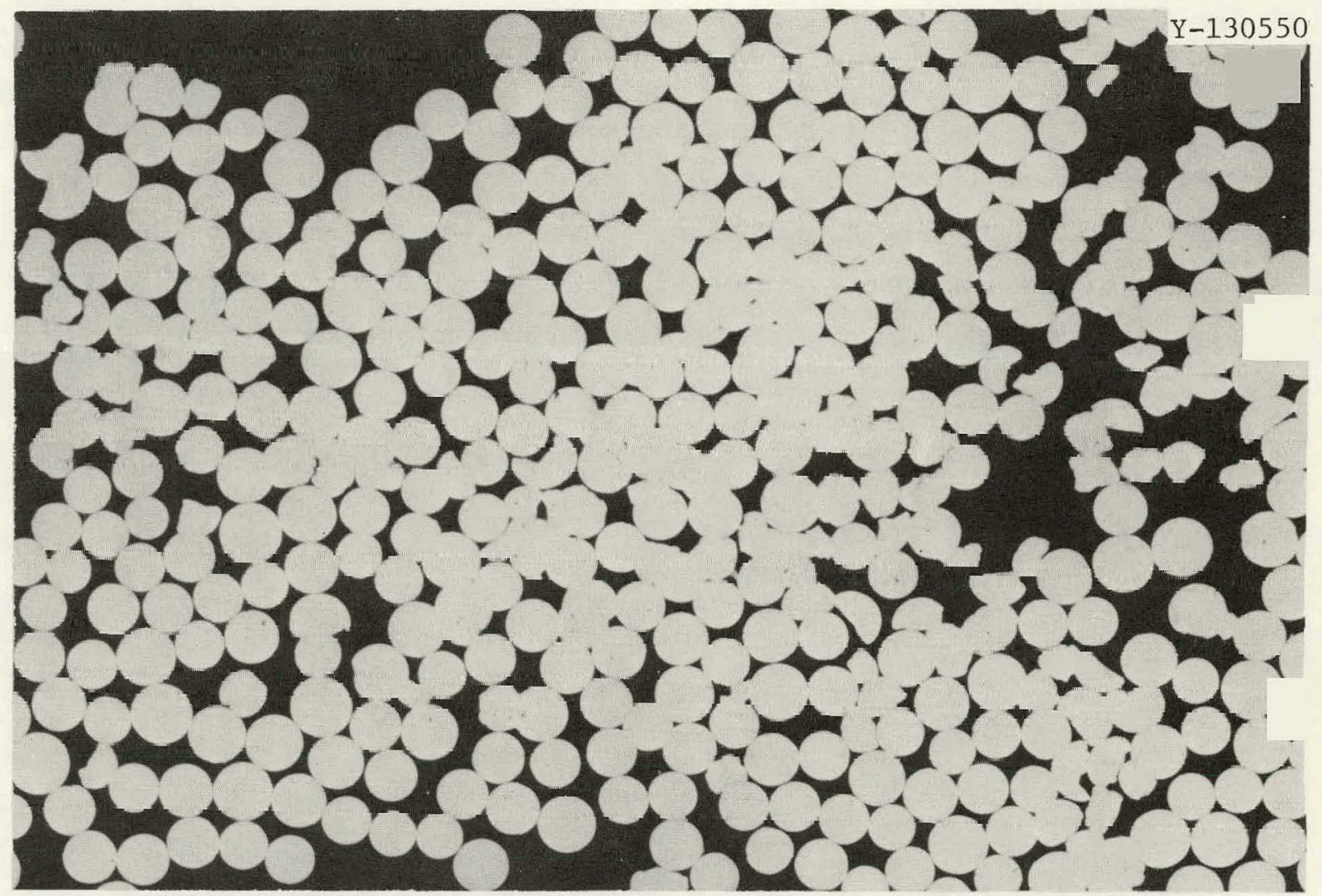

Fig. 17. Radiograph of Carbonized and Converted Duolite C-464 Resin Uranium-Loaded by Ammonia Neutralization Method. 20x. 
Table 2. Screen Analyses and Radiographic Size Measurements of Duolite C-464 Resin Particles After Carbonization and Conversion

\begin{tabular}{|c|c|c|c|c|c|c|c|}
\hline \multirow{2}{*}{ Run } & \multirow{2}{*}{ Method } & \multicolumn{3}{|c|}{ Radiographic Size, $\mu \mathrm{m}$} & \multirow{2}{*}{\multicolumn{2}{|c|}{$\begin{array}{c}\text { Screen Analyses, } \\
\text { (wt } \%)\end{array}$}} & \multirow{2}{*}{$\mu \mathrm{m}$} \\
\hline & & Maximum & Mean & Minimum & & & \\
\hline V54 & $\begin{array}{c}\text { Ammonia } \\
\text { Neutralization }\end{array}$ & 371 & 315 & 258 & $\begin{array}{l}+360 \\
(5.6)\end{array}$ & $\begin{array}{c}-360,+250 \\
(85.7)\end{array}$ & $\begin{array}{l}-250 \\
(8.7)\end{array}$ \\
\hline V48 & $\mathrm{UO}_{3}$ & 398 & 382 & 345 & $\begin{array}{l}+400 \\
(0.4)\end{array}$ & $\begin{array}{c}-400,+330 \\
(98.9)\end{array}$ & $\begin{array}{l}-330 \\
(0.7)\end{array}$ \\
\hline
\end{tabular}

\section{Optica1 Microscopy}

Based on the previous experience, as discussed in the section on Amberlite, the first step was to crack open some of the particles by crushing with hand-held micrometer calipers. Color gradation from the center to the edge can be seen (Fig. 18), but the white centers and glasslike material found in IRC-72 resin are not present.

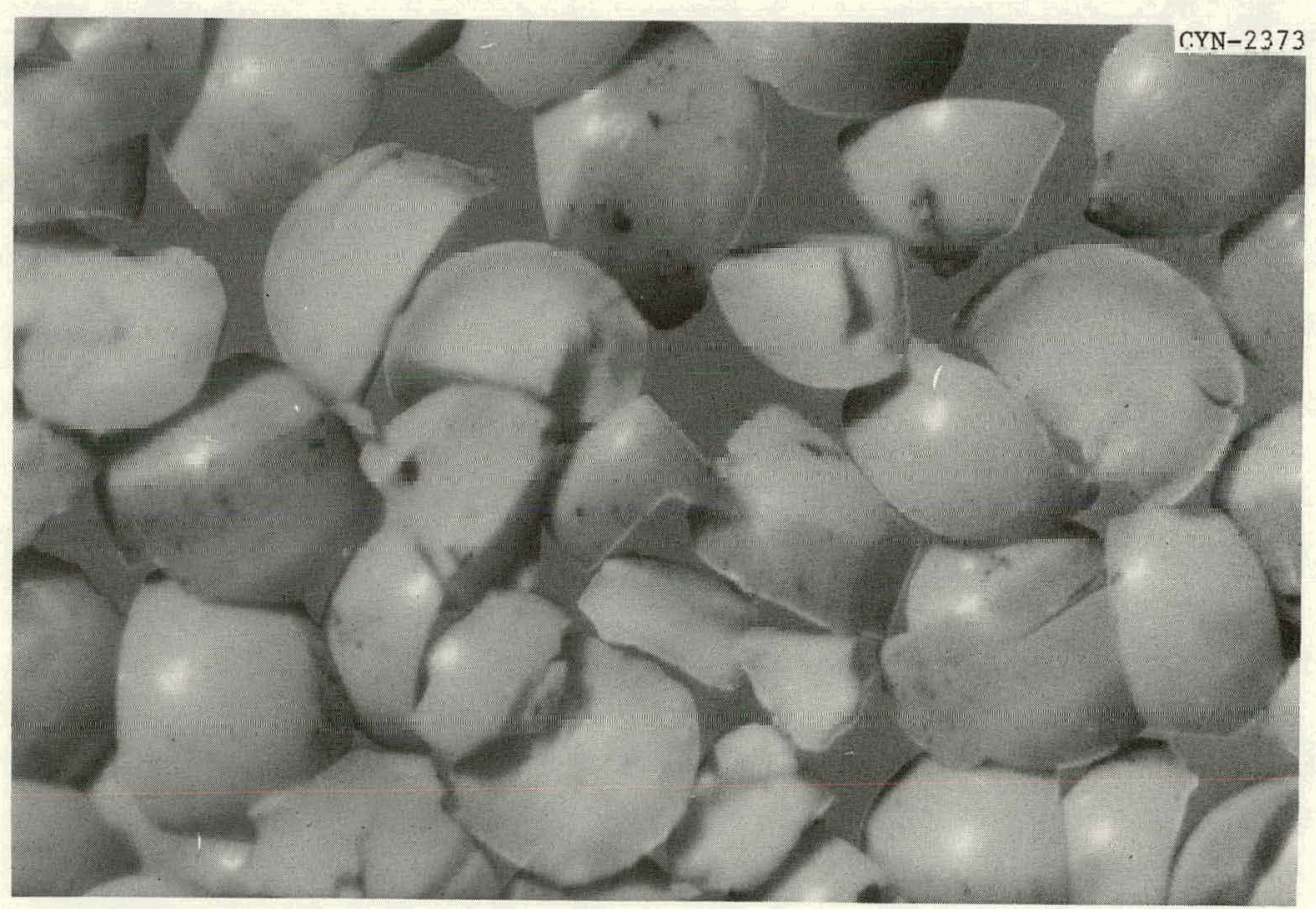

Fig. 18. Duolite C-464 Weak Acid Resin Microspheres Uranium-Loaded via Ammonia Neutralization Method and Deliberately Cracked Open for Inspection. $80 \times$. Reduced $24 \%$. 
For comparison, Duolite C-464 resin loaded by the $\mathrm{UO}_{3}$ method $^{3}$ was also cracked open for inspection (Fig. 19). In these particles no center-to-edge color gradation can be seen.

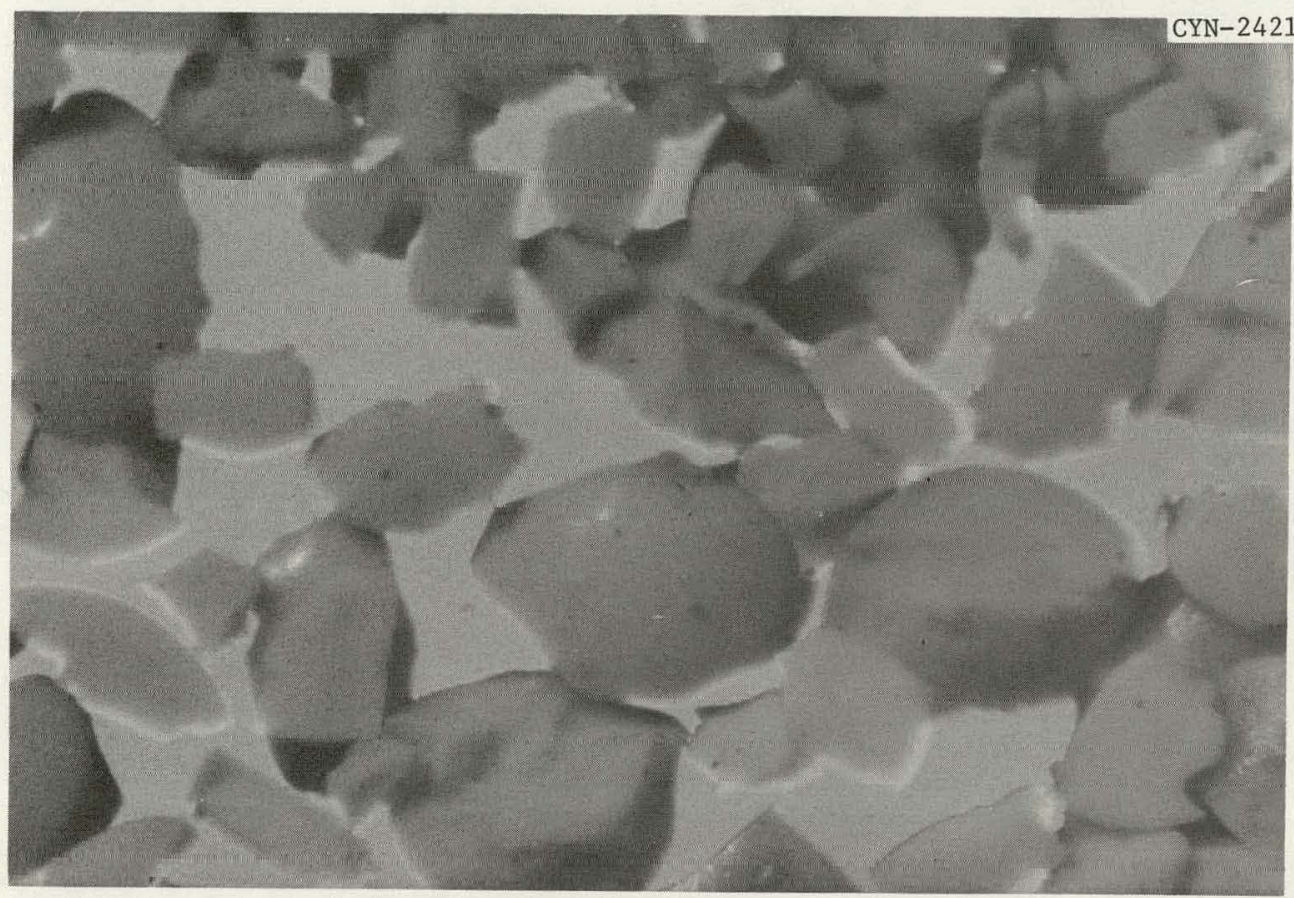

Fig. 19. Duolite C-464 Weak Acid Resin Microspheres Loaded via the $\mathrm{UO}_{3}$ Method and Deliberately Cracked Open for Inspection. 100×. Reduced $24 \%$.

Photomicrographs of whole microspheres from this same batch revealed particles with two types of defects; namely, a football shape (Fig. 20) and a ruptured surface (Fig. 21). * Such defects are common in commercially supplied weak acid resin microspheres. Shape separation by the vibrating table method ${ }^{8}$ removes many of the defective particles, but seems to be less effective in removing the types seen in Figs. 20 and 21 . These types are more often found in Duolite C-464 than in Amberlite IRC-72.

\section{Electrun Microprobe}

The indication of nonuniform intraparticle loading was clear from the appearance of the cracked particles in Fig. 18. In order to assess

\footnotetext{
* Color photographs of Figs. $18-21$ are available upon request.
} 


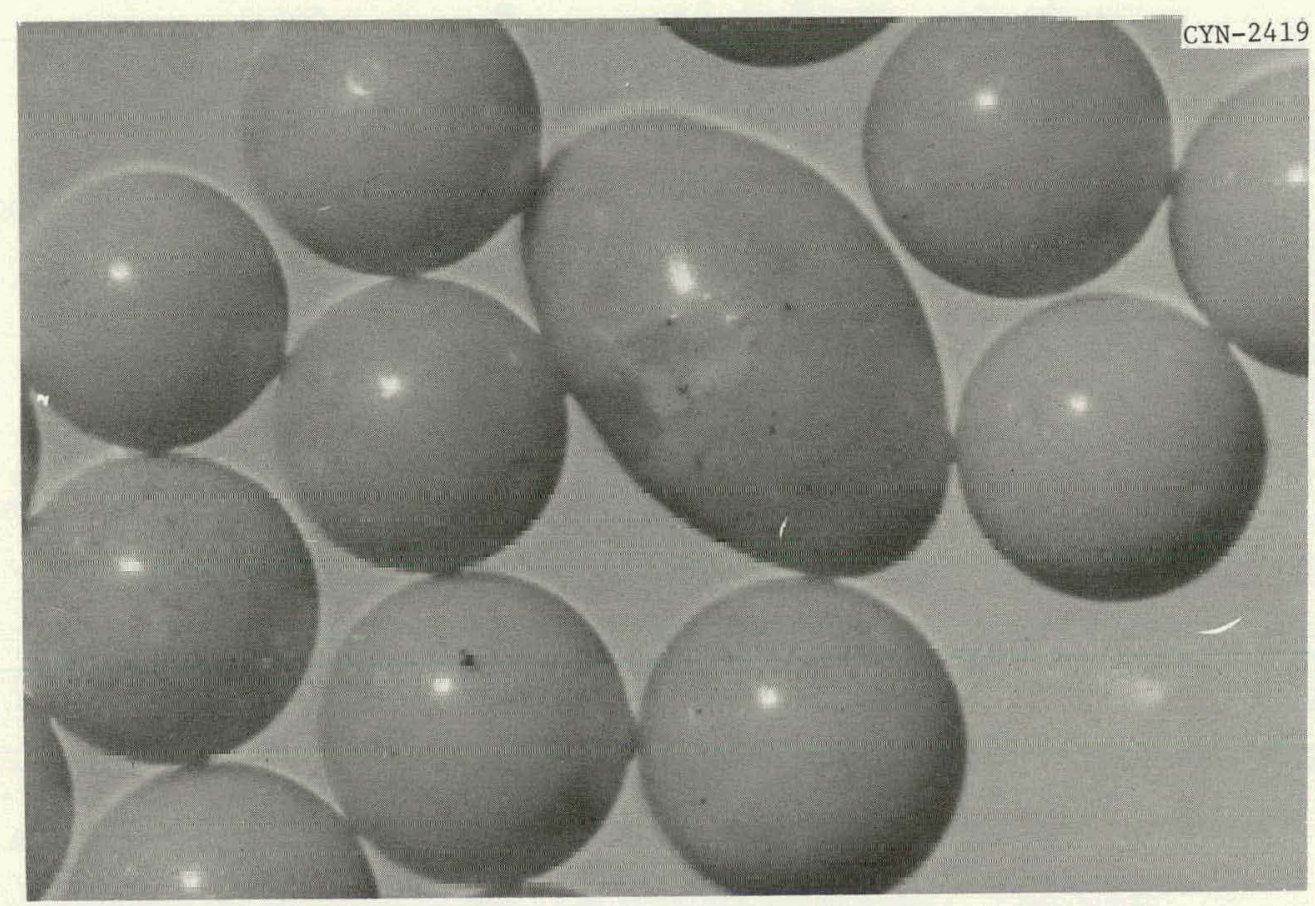

Fig. 20. Duolite C-464 Weak Acid Resin Microspheres Uranium-Loaded by the $\mathrm{UO}_{3}$ Method. Note the unusual football-shaped particle. 100×. Reduced 24\%.

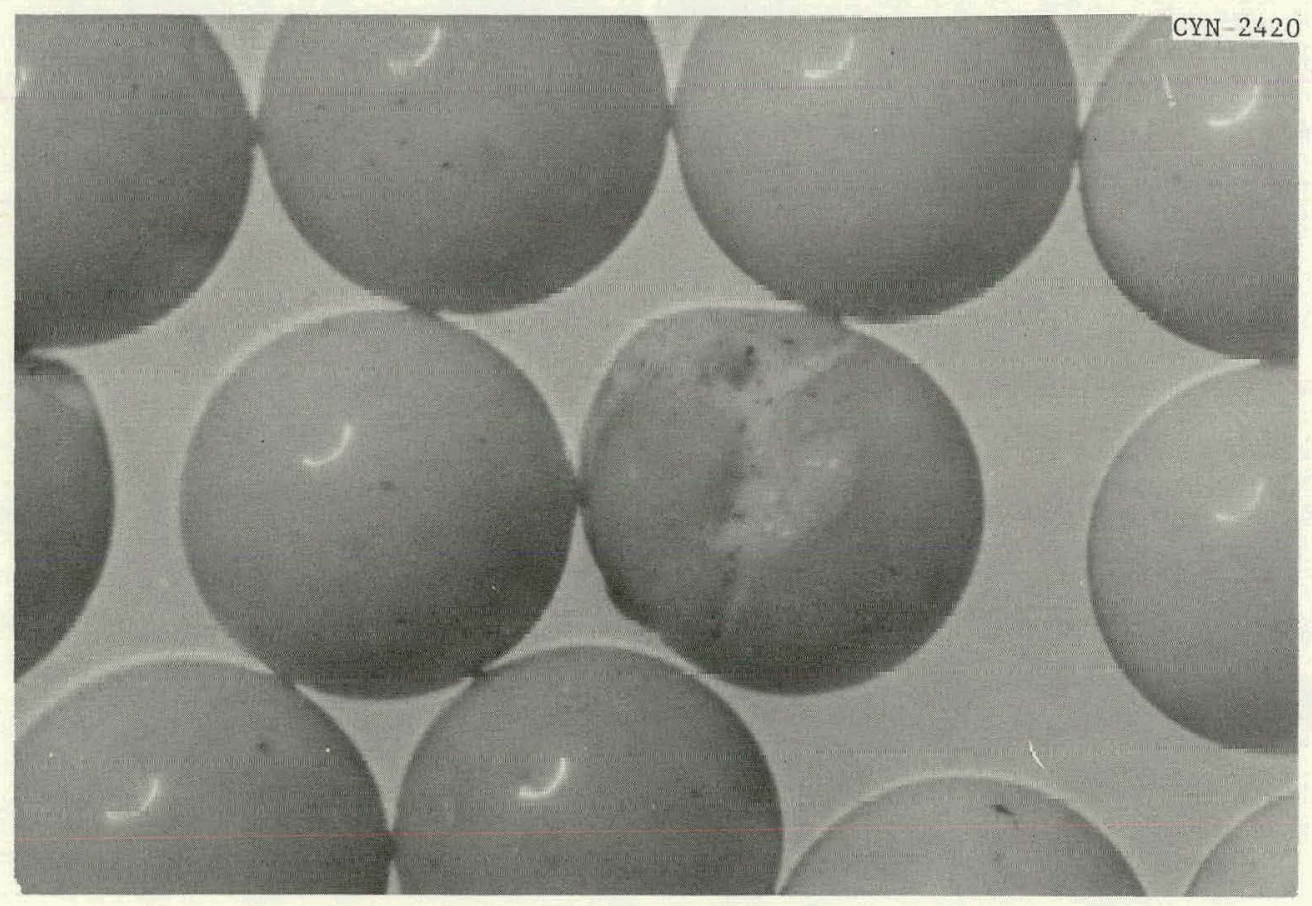

Fig. 21. Duolite C-464 Weak Acid Resin Microspheres Uranium-Loaded by the $\mathrm{UO}_{3}$ Method. Note the relatively rare surface rupture in one of the particles. $100 \times$. Reduced $24 \%$. 
this intraparticle variation, we performed electron microprobe analyses on sectioned microspheres. Optical photomicrographs of several such sectioned particles are shown in Figs. 22 to 25, and electron microprobe scans of two selected particles are shown in Figs. 26 and 27.

As seen in Fig. 22, most particles consist of a relatively roughappearing core surrounded by a slightly smoother region, in turn surrounded by a much thinner outer shell. The thickness of all regions varies, especially the core and the material surrounding it. The thickness of the outer shell appears less variable. Under the instrument conditions used, the "effective diameter" of the electron beam, that is, the area from which the $x$-rays emanated, is estimated to be about $5 \mu \mathrm{m}$; the actual beam diameter is much 1ess. Judging from measurements made on the photomicrographs of Figs. 26 and 27, the width of the thin outer shell is about $15 \mu \mathrm{m}$. Some rounding of a scan at the edge of a

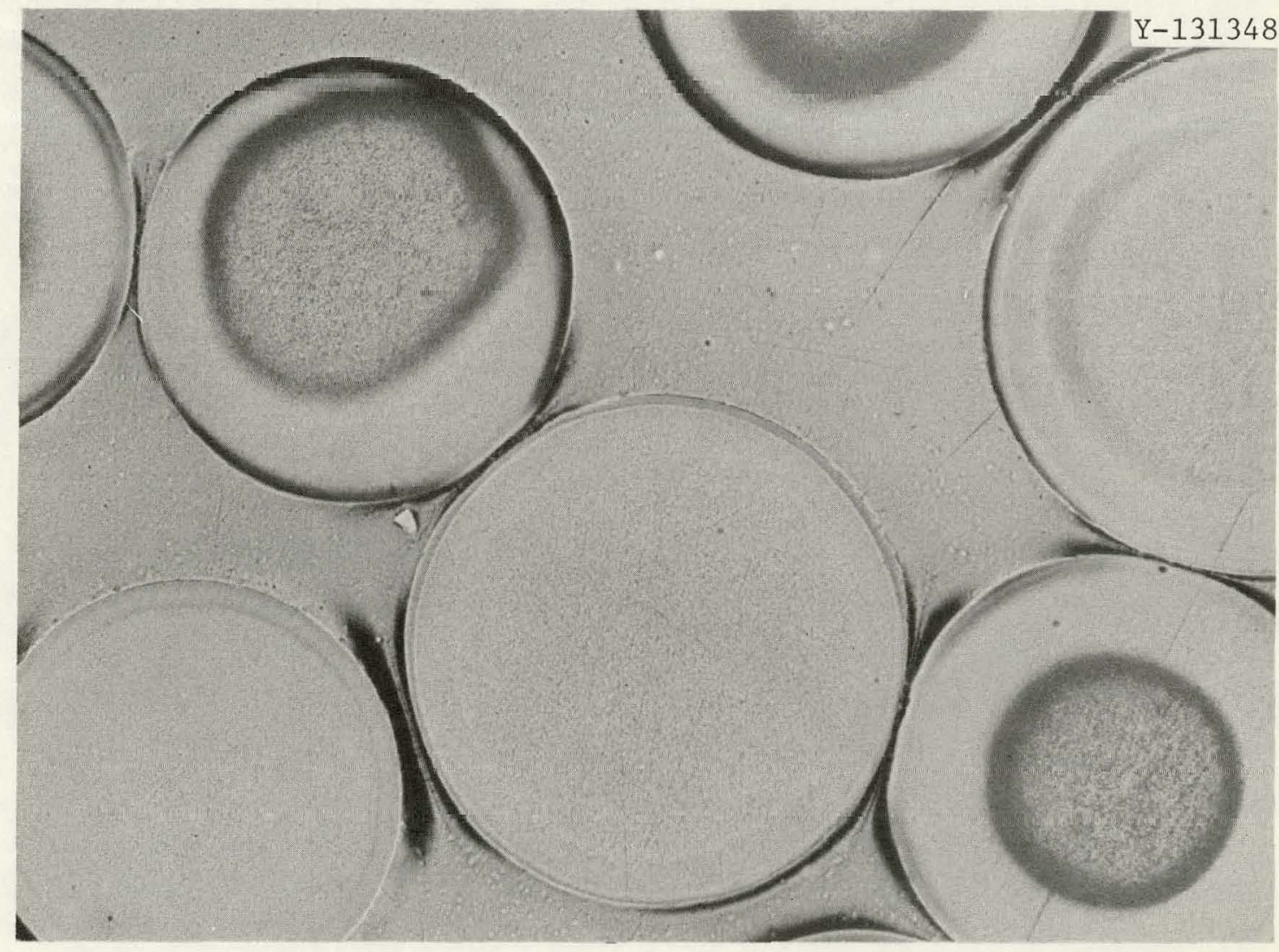

Fig. 22. Photomicrograph of Duolite C-464 Weak Acid Resin Microspheres Uranium-Loaded by the Ammonia Neutralization Method, Sectioned for Electron Beam Microprobe Examination. 100x. 


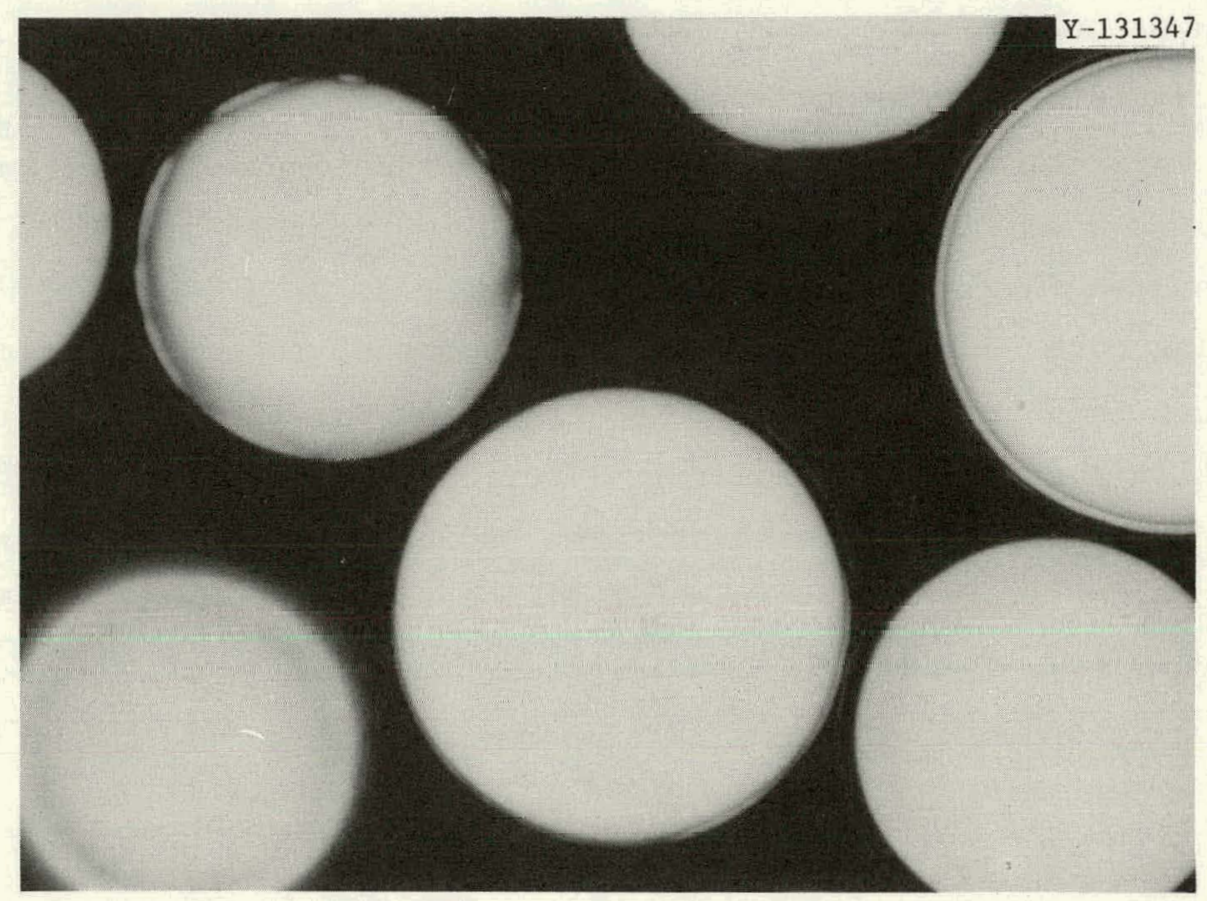

Fig. 23. Polarized Light Photomicrograph of Duolite C-464 Weak Acid Resin Microspheres Uranium-Loaded by the Ammonia Neutralization Method, Sectioned for Electron Beam Microprobe Examination. Same field as Fig. 22. 100×. Reduced $19 \%$.

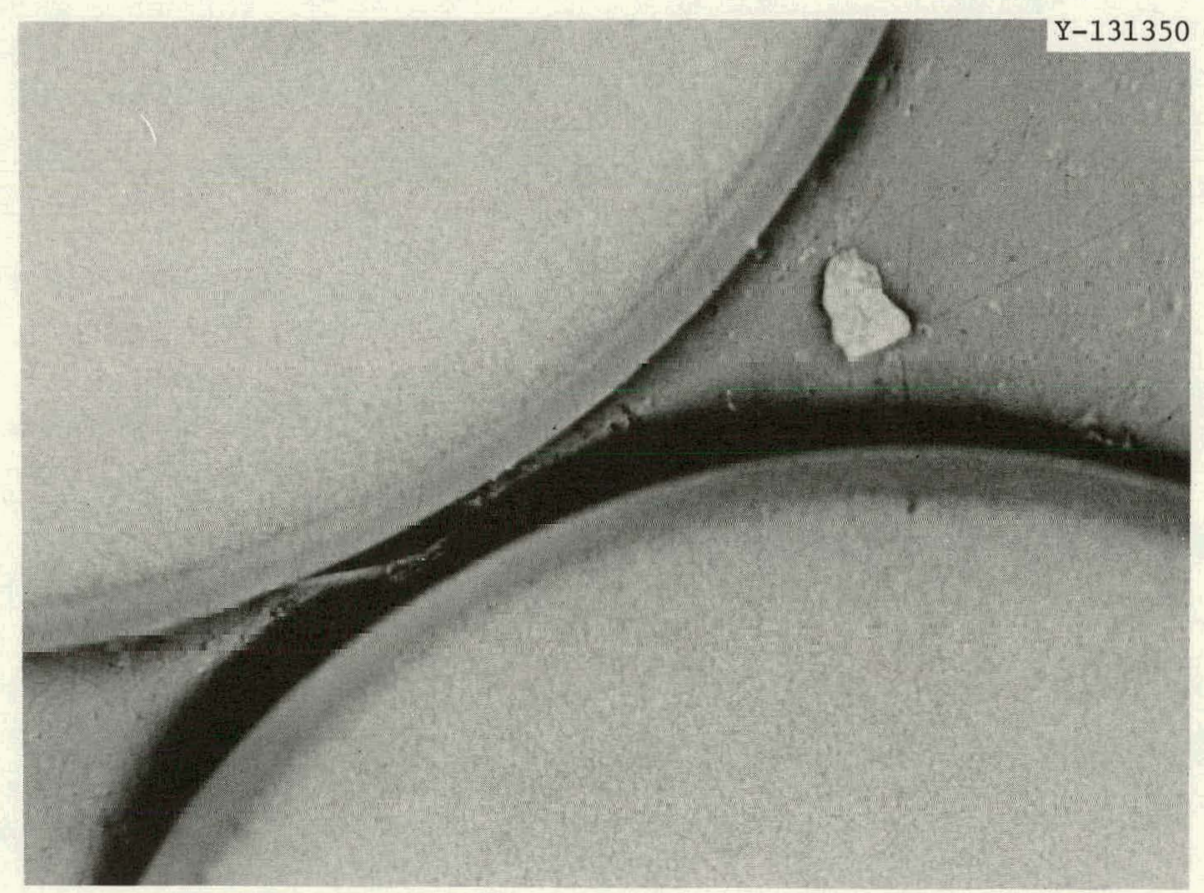

Fig. 24. Photomicrograph of Edges of Duolite C-464 Weak Acid Resin Microspheres Uranium-Loaded by the Ammonia Neutralization Method, Sectioned for Electron Beam Microprobe Examination. 500×. Reduced $19 \%$. 


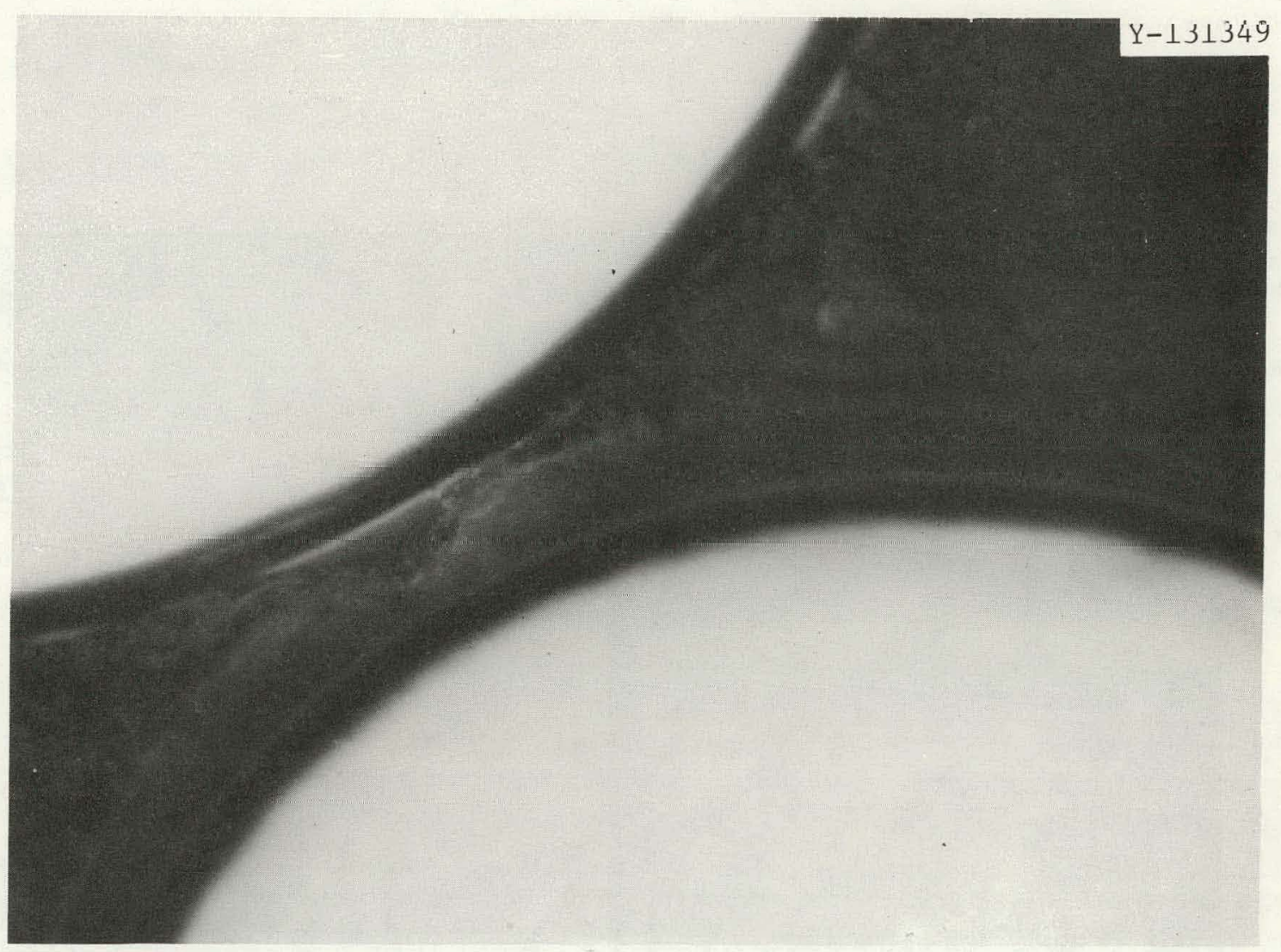

Fig. 25. Polarized Light Photomicrograph of Edges of Duolite C-464 Weak Acid Resin Microspheres Uranium-Loaded by the Ammonia Neutralization Method, Sectioned for Electron Beam Microprobe Examination. Same field as Fig. 24. 500x.

specimen due to the finite width of the beam is to be expected but the edge plateaus seen in the scans of Figs. 26 and 27 are too wide, and hence must be real.

From Figs. 26 and 27, it is apparent that the core and thin outer she11 were considerably underloaded with respect to the other region. Though similar to the situation observed in the sample of Amberlite IRC-72 resin discussed earlier (e.g., Figs. 13 and 14), note that the change in concentration is much more gradual between the center and the high-uranium material surrounding it. This observation suggests that the problem in this instance is not one of a marked change in resin structure. 


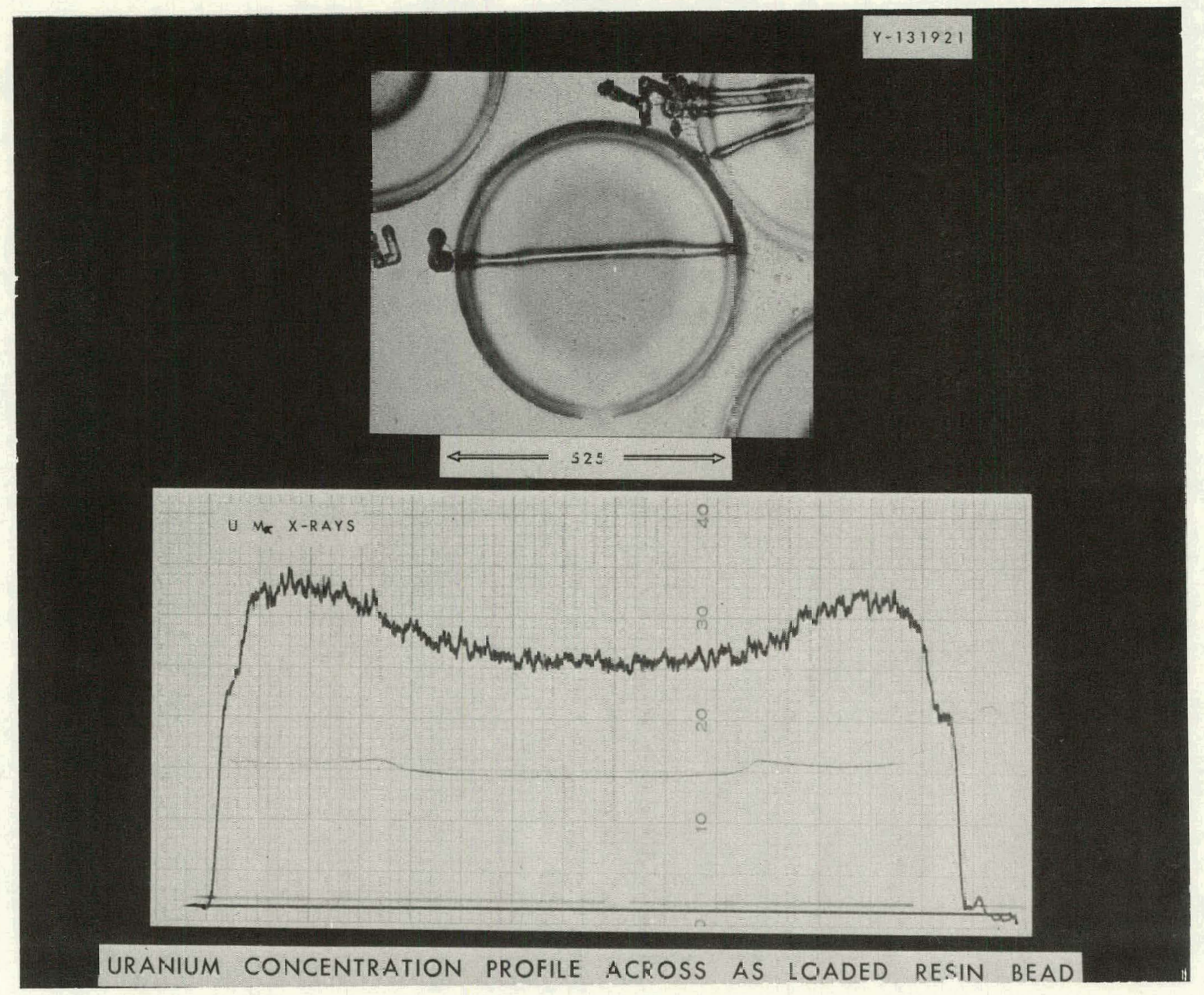

Fig. 26. Photomicrograph and Electron Microprobe Scan of Sectioned Duclite C-464 Weak Acid Resin Microsphere Uranium-Loaded by the Ammonia Neutralization Method. 110x. Reduced 29.5\%. 


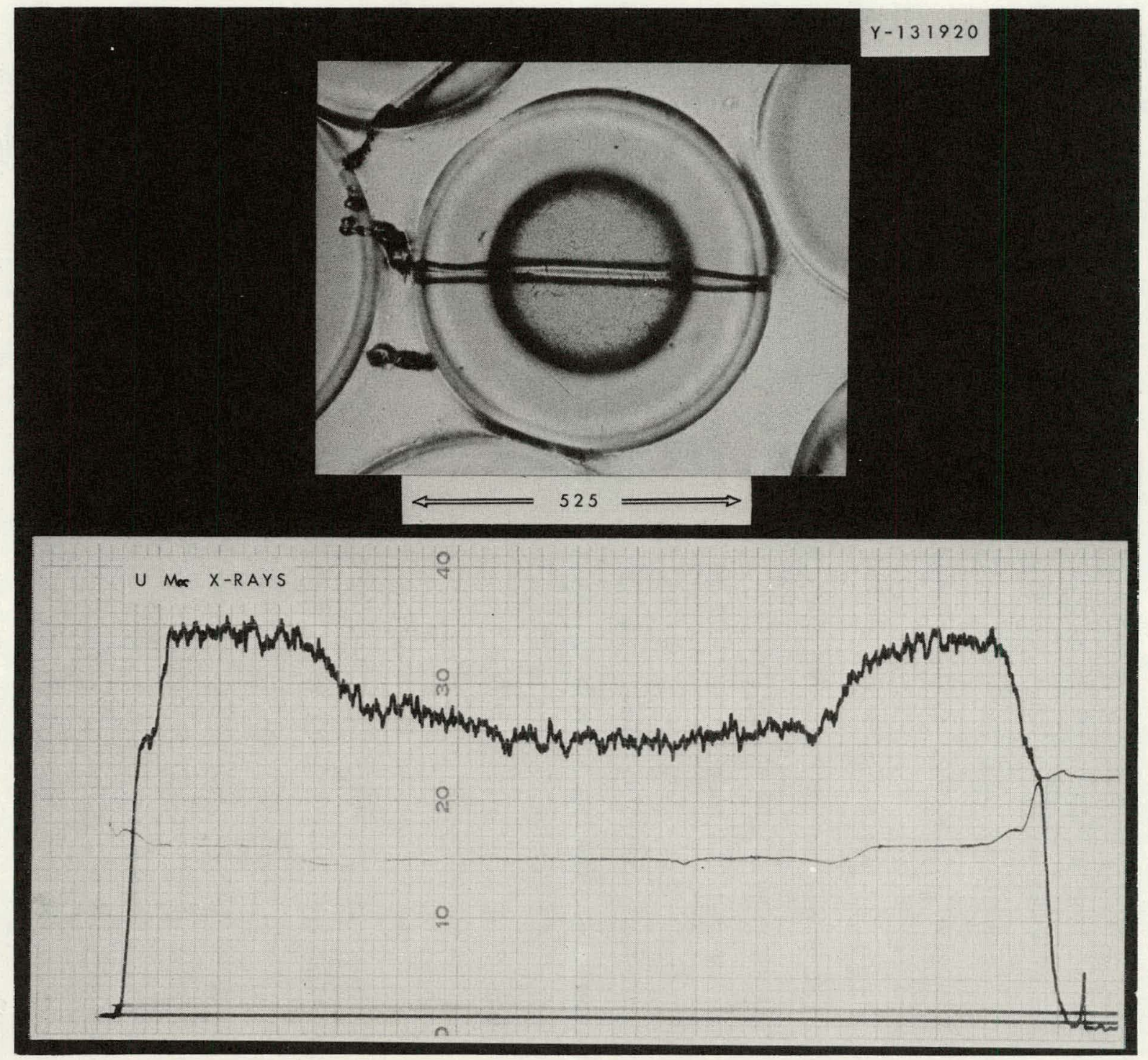

Fig. 27. Photomicrograph and Electron Microprobe Scan of Sectioned Duolite C-464 Weak Acid Resin Microsphere Uranium-Loaded by the Ammonia Neutralization Method. 110×. Reduced $22 \%$. 


\section{Discussion}

Loading of weak acid resin via the ammonia neutralization method is a two-step (perhaps three-step) process. ${ }^{12}$ In step 1 (a) the ammonium form resin contacts an acidic uranyl nitrate solution. Approximately $50-75 \%$ of the ultimate uranium loading is accomplished here. In step 1(b) the $\mathrm{pH}$ of the solution is adjusted to slightly basic to precipitate most of the uranium as ammonium diuranate ( $\mathrm{ADU}$ ). The resin bed itself is used as a filter to collect the precipitate. The spent solution is drained and discarded. In step 2, the resin bed contacts another acidic uranyl nitrate solution. The ADU precipitate redissolves and the loading of the resin is completed.

The profiles of Figs. 26 and 27 are likely associated with precipitation effects. ${ }^{3}$ The equilibria involved in the loading of ammonium-form resin from acidic uranyl nitrate solutions has been discussed by P. A. Haas in detail. ${ }^{14}$ In step 1 (a) the impregnating solution has a $\mathrm{pH}$ of about 3 . The unloaded ammonium-form resin, if placed in pure water, produces a $\mathrm{pH}$ of about 10. During step 1(a), then, a pH gradient must exist between the edge of the particle and its center. Between a $\mathrm{pH}$ of 3 and 4 , the uranium will precipitate from the uranyl nitrate solution as hydrated oxides or hydroxides and as ammonium diuranate at higher $\mathrm{pH}$ values. The heaviest precipitation might occur in the outer-most regions where contact with the solution is first made and diminish in extent toward the center, producing the profiles seen in Figs. 26 and 27 . In step 2 the $\mathrm{pH}$ of the solution is initially about 1.5 and does not rise above 3 . Under these conditions the precipitates would dissolve and complete the exchange reaction. However, if enough contact time were not allowed for the products of precipitation to dissolve completely, the nonuniform concentration profiles would be retained. Support for this hypothesis may be in the observation by Notz ${ }^{9}$ that nonuniform or "shell" loading of uranium is possible with sodium- or ammonium-form resins, but not with hydrogenform resins.

The reason for the low concentration in the narrow outer rim is less obvious. In step 1(a), this region, being closest to the bulk solution, would tend to remain at a low $\mathrm{pH}$ and precipitation would be less likely. 
However,..it is.difficult to rationalize why the concentration at the outer rim is so much lower than even the center of the particle. The appearance of the rim region, as seen in Figs. 22-25, suggests that its structure may be considerably different from the interior material. It could be that an error in manufacture of the resin bead could have produced a rim with a reduced exchange capacity as, it is speculated, probably occurred in the case discussed before. Certainly, the evidence of structural damage here is by no means as obvious as in the case of, for example, the glass-like material seen in the previous samples.

Though the gradation in uranium loading is an obvious defect, it may not be the main cause of microsphere breakage. The best clue to what may be the major cause is probably the $51 \% \mathrm{U}$ loading on the dried resin as seen in Table 1. The usually observed maximum loading (dry basis) of either Duolite: $\mathrm{C}-464$ or Amberlite IRC-72 resin is something less than 48 .wt \% as seen, for example, in the loadings of the resin used in runs V55, 47, and 48, in Table 1 , and in ref. 12. Recent work by P. A. Haas ${ }^{15}$ indicates that the reason why loadings above $48 \%$ are not achieved may be the formation of a uranyl hydrate. This limit of $48 \%$ only applies when ali the loading is by true ion-exchange. The $51 \% \mathrm{U}$ content of this batch implies that some of the uranium was present as a precipitate.

Further support for this precipitation hypothesis may be in the density differences between the converted Duolite C-464 batches in Table 1 . Note the density of $2.59 \mathrm{Mg} / \mathrm{m}^{3}$ for $\mathrm{UO}_{3}$-loaded $\mathrm{V} 48$ versus $3.20 \mathrm{Mg} / \mathrm{m}^{3}$ for V54. Duolite C-464, like Amberlite IRC-72, is a macroreticular resin. It is in the macropores of the microsphere that the precipitation would be expected to occur. A recent study by G. W. Weber et ai. ${ }^{16}$ showed that the macroporosity of uranium-loaded Duolite C-464 or Amberlite IRC-72 resin is maintained through conversion although significant changes of the pore size and structure occur along with an overall shrinkage of the resin bead. Thus, a converted particle with macropores containing a precipitate would be expected to show a higher final density, as seems to be the case in the present situation.

From the present data, it is impossible to ascertain whether the cracking of the particles occurred during carbonization or conversion. The study by Weber et al. ${ }^{16}$ also showed that while the resin particle as 
a whole shrinks in volume about 30 to $40 \%$ during carbonization, the size and distribution of the macropores remains about the same; the greatest shrinkage of the pores occurs during conversion. Cracking during carbonization seems unlikely in that ammonium diuranate decomposes in the same temperature range as the resin ${ }^{17}$ (about 250 to $500^{\circ} \mathrm{C}$ ). If precipitates were present in the pores, it would be expected that cracking would occur mostly during conversion. This was in fact observed recently in a subsequent batch of Duolite C-464 loaded by the ammonia neutralization method ${ }^{18}$ that was analyzed for cracking after carbonization and conversion.

I.t is important to understand that the batch of resin discussed here was loaded during a period when the 1 naring proceoo wao being developed, and that recent improvements in the ammonia neutralization method are reported to have alleviated the problem of cracking. ${ }^{12}$

\section{SUMMARY AND RECOMMENDATIONS}

The two major instances of weak acid resin failure during this development program were intensively investigated. The first failure occurred with a batch of Amberlite IRC-72 resin loaded with uranium by the $\mathrm{UO}_{3}$ method. During pneumatic transfer experiments, a relatively small percentage of resin-form microspheres broke, and about half of the microspheres in the batch broke during carbonization. Intra-particle varfaclons in uranium concentration and resin structure were observed. The cause of the fallure was probably structural abnormalities that resulted from an improper step in the manufacture of the resin microspheres.

The second failure occurred during the carbonization and conversion of a batch of Duolite C-464 weak acid resin 1 naded by the ammonia neutralization method. We nhserved intra-partir.1e variatione in uranium concentration, and believe that the failure was caused by an overloading condition in which uranium compounds precipitated in the resin pores.

These two batches of resin are the only ones to fail out of many batches of uranium-loaded weak acid resin observed to date; all the others have performed well. 
The results clearly indicate that the effects of abnormalities may not appear until well after the resin is loaded. Therefore, for any large-scale loading operation we recommend the implementation of appropriate quality control measures and inspection, such as were performed in this study, to prevent the waste of carbonizing and converting defective batches.

\section{ACKNOWLEDGMENTS}

The photography is that of E. P. Griggs and J. W. Nave. The SEM and electron microprobe analyses were performed by $R$. S. Crouse. The report was edited by $R$. R. Ihrig and prepared for reproduction by Connie Harrison.

\section{REFERENCES}

1. C. B. Pollock and R. L. Beatty, "Development of Inert Dimensionally Stable Microsphere Kernels for Coated-Particle Irradiation Tests in HFIR," Gas-Cooled Reactor Program Semiannu. Prog. Rep. Sept. 30, 1969, ORNL-4508, p. 9.

2. J. L. Scott, J. M. Leitnaker, and C. B. Pollock, "Preparation of Coated Fuel Particles from Ion-Exchange Resin," Gas-Cooled Reactor Program Semiannu. Prog. Rep. Mar. 31, 1970, ORNL-4589, pp. 3-7.

3. P. A. Haas, HTGR Fuel Development: Use of $\mathrm{UO}_{3}$ to Load Cation Exchange Resin for Microsphere Preparation, ORNL-TM-3817, September 1972.

4. Personal communication, D. R. Johnson, October 1974.

5. Personal communication, D. R. Johnson, November 1974.

6. Personal communication, D. R. Johnson, January 1975.

7. P. A. Haas, HTGR Fuel Development: Loading of Uranium on Carboxylic Acid Cation-Exchange Resins Using Solvent Extraction of Nitrate, ORNT.-TM-4955 (September 1975).

8. F. J. Furman, J. T. Meador, and J. D. Sease, Microsphere Handling Techniques, ORNL-TM-2782 (March 1970) pp. 15-18.

9. K. J. Notz and P. A. Haas, Gas-Cooled Reactors Programs Annu. Prog. Rep. Dec. 31, 1972, ORNL-4911, p. 31. 
10. K. A. Kun and R. Kunin, "The Pore Structure of Macroreticular Ion Exchange Resins, J. of Polym. Sci., Part C(16): 145779 (1967).

11. R. L. Albright, Rohm and Haas Co., personal communication, November 12, 1975.

12. R. J. Precourt and R. O. Whipple, The WAR Fissize Kermel Process, GA-A13902 (Apri1 12, 1976).

13. P. A. Haas, personal communication, August 1976.

14. P. A. Haas, personal communication, April 1975.

15. P. A. Haas, personal communication, April 1976.

16:" G. W. Weber, R. L. Beatty, and V. J. Tennery, Properties of Carbonized and Converted Uranium-Loaded Weak Acid Resin, ORNL-5201 (February 1977).

17. K. J. Notz et al., unpublished data.

18. J. A. Carpenter, Jr., unpublished data. 
ORNL/TM-6067

Distribution

Category UC-77

INTERNAL DISTRIBUTION

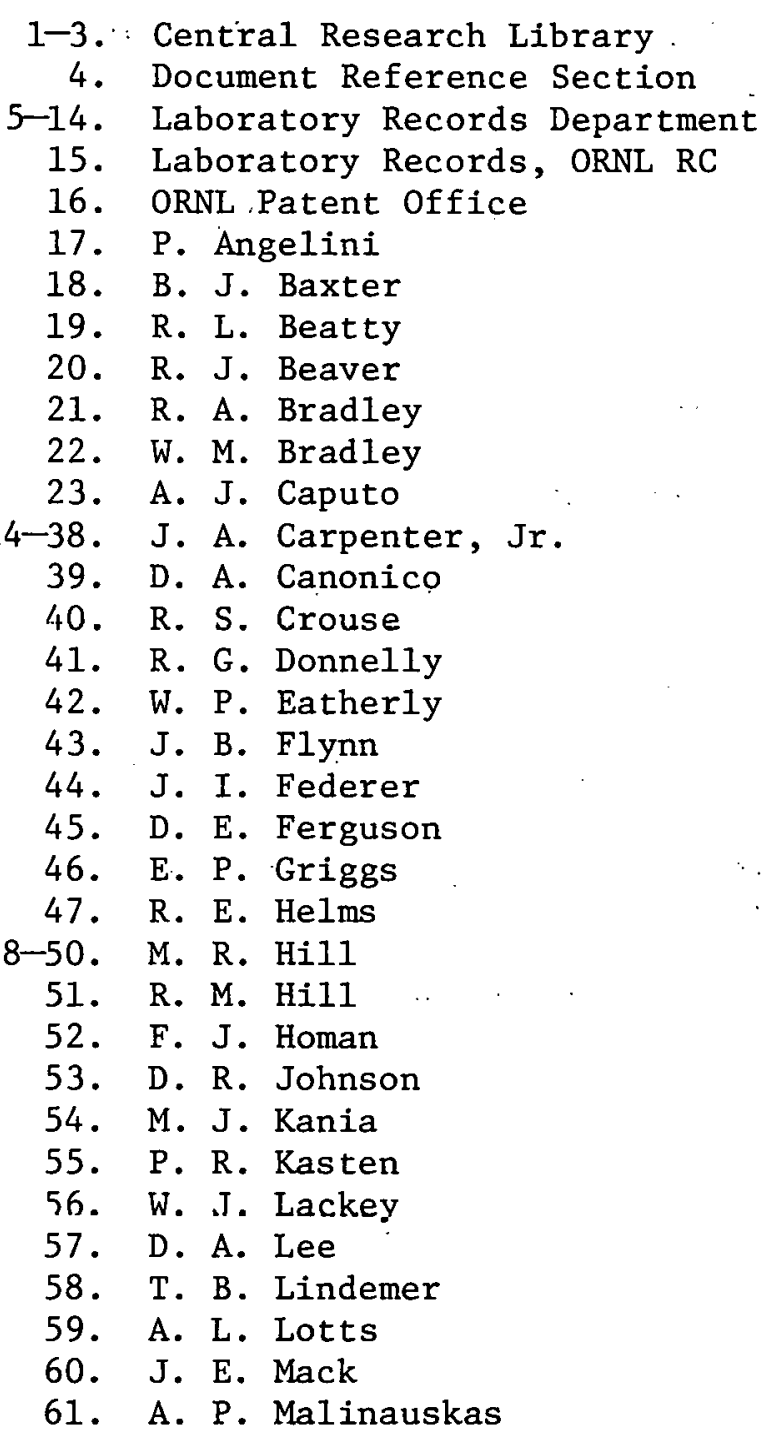

62. M. M. Martin

63. S. R. McNeany

64. C. S. Morgan

65. J. W. Nave

66. K. J. Notz

67. A. R. Olsen

68. A. E. Pasto

69. R. L. Pearson

70. D. P. Reid

71. J M Robbins

72. J. E. Rushton

73. T. F. Scanilan

74. C. D. Scott

75. J. E. Selle

76. D. P. Stinton.

77. R. R. Suchomel

78. V. J. Tennery

79: B. A. Thiele

80. S. M. Tiegs

81. T. N. Tiegs

82. D. B. Trauger

83. G. W. Weber

84. G. C. Wei

85. J..R. Weir, Jr.

86. R. P. Wichner

87. R. G. Wymer

88. C. S. Yust

89. R. W. Balluffi (consultant)

90. P. M. Brister (consultant)

91. W. R. Hibbard (consultant)

92. Hayne Palmour III (consultant)

93. N. E. Promisel (consultant)

94. D. F. Stein (consultant)

EXTERNAL DISTRIBUTION

95-96. ERDA DIVISION OF REACTOR NUCLEAR RESEARCH AND APPLICATIONS, Washington, DC 20545

Director

97. ERDA IDAHO OPERATIONS OFFICE, P.0. Box 2108, Idaho Falls, ID 83401 Barry Smith 
EXTERNAL DISTRIBUTION (Continued)

98. ERDA OFFICE OF PROGRAM MANAGEMENT, RESEARCH AND SPACE PROGRAMS, P.0. Box 81325, San Diego, CA. 92138

J. B. Radcliffe

99. ERDA SAN FRANCISCO OPERATIONS OFFICE, 1333 Broadway, Wells Fargo Building, Oakland, CA 94612

Manager

100-102. ERDA DIVISION OF WASTE MANAGEMENT, PRODUCTION AND PROCESSING, Washington, DC 20545

Chlef, Technónologỹy branch

Chief, Projects Branch

Chief, Industrial Programs Branch

103-105. ERDA OAK RIDGE OPERATIONS OFFICE, P.O. BOX E, Oak Ridge, TN 37830

Director, Research and Technical Support Division

Director, Reactor Division

F. E. Dearing, Reactor Division

106-282. ERDA TECHNICAL INFORMATION CENTER, P.0. Box 62, Oak Ridge, TN 37830

For distribution as shown in TID-4500 Distribution Category, UC-77 (Gas-Cooled Reactor Technology)

283-290. ERDA Exchange Agreements with Germany and Dragon Project 